\title{
Balıkesir Florasında İstilacı Karaktere Sahip Yerli Bitki Taksonları Üzerine Bir Araştırma
}

\section{Fatih SATIL ${ }^{1}$, Selami SELVİ2, Gülendam TÜMEN3}

${ }^{1,3}$ Balıkesir Üniversitesi, Fen-Edebiyat Fakültesi, Biyoloji Bölümü, Çağış Yerleşkesi, 10145, Balıkesir, ${ }^{2}$ Balıkesir Üniversitesi, Altınoluk Meslek Yüksekokulu, Tıbbi ve Aromatik Bitkiler Programı,10870, Balıkesir, Türkiye

${ }^{1}$ https://orcid.org/0000-0002-4938-1161, ${ }^{2}$ https://orcid.org/0000-0003-3848-5798, ${ }^{3 h t t p s: / / o r c i d . o r g / 0000-0002-7457-3341 ~}$

$\square$ : fsatil@gmail.com

\section{ÖZET}

$\mathrm{Bu}$ çalışmada, Balıkesir florasında yayılış gösteren istilacı karaktere sahip bitki taksonları belirlenerek, bu taksonların habitatlardaki dağılımı ve taşıdığı ekolojik riskler ortaya konulmuştur. Bu amaçla, Balıkesir ve ilçelerinde periyodik olarak gerçekleştirilen arazi çalışmalarına ek olarak bölgede daha önce tarafımızca yapılmış olan floristik gözlem ve çalışmalarda elde edilen veriler değerlendirilmiştir. Araştırma sonucunda; Balıkesir florasında 44 familyaya ait 172 cins ve 271 takson'un istilaci karaktere sahip bitkiler sınıfına dâhil edilebileceği görülmüştür. Bunlar içerisinde en fazla takson içeren familyalar sırasıyla; Asteraceae (45 takson, \%16.6) Poaceae (38 takson, \%14) ve Fabaceae (33 takson, \%12.2)'dir. En fazla takson içeren ilk üç cins ise; Trifolium L. (10 takson, \%3.7), Carex L. (6 takson, \%2.2) ve Juncus L. (6 takson, \%2.2)'dur. Taksonların habitat tiplerine göre dağılımında ise ilk üç habitat; E1. kuru otlaklar" (136 takson, \%50.2), "J1. şehir merkezleri, sürekli bina yapıları" (31 takson, \%11.4), ve "E5.1 antropojenik bitki durumları" (30 takson, \%11.1) şeklindedir. İnsan müdahaleleri/etkileri sonucunda ortaya çıkan boş araziler, bölgede bilinçsiz ve aşırı otlatma, çayır ve meralarda otlatmaya karşı dirençli olan bu istilacı türlerin yerleşmesine fırsat sağlamıştır. Bu durum alanın floristik yapısının değişmesine, ayrıca çayır ve mera kalitesinin düşmesi sonucunda tür zenginliğinin azalmasına neden olmuş ve tarımı olumsuz etkilemiştir. $\mathrm{Bu}$ nedenle bu taksonların yayılış alanları belirli periyotlarda gözlemlenmeli ve gerekli önlemler alınmalıdır. Bu amaçla, taksonlar teşhis edildikten sonra, bu konuda yetkili olan paydaşlara durumun bildirilmesi gerekir. Önemli görülen türler için acil müdahale çerçevesinde; yayılmanın önlenmesi amacıyla uygun yöntemler kullanılmalıdır.

\section{A Research on Native Plant Taxa with Invasive Character in Flora of Balıkesir}

\section{ABSTRACT}

In this study, native plant taxa with invasive character that spread in flora of Balıkesir were determined. Their distribution depending on habitat types and their ecological risks were revealed. For this purpose, in addition to the field studies conducted periodically in Balıkesir and its districts, data of floristic observations taken from the same region were evaluated. As a result of the research; 172 genera and 271 taxa belonging to 44 families spreading in flora of Balıkesir were included in the invasive plants with invasive character. Among these, the families containing the most taxa were Asteraceae (45 taxa, 16.6\%), Poaceae (38 taxa, 14\%) and Fabaceae (33 taxa, 12.2\%). The first three genera that contain the most taxa were Trifolium L. (10 taxa, 3.7\%), Carex L. (6 taxa, 2.2\%) and Juncus L. (6 taxa, 2.2\%). In the distribution according to habitat types of taxa, the first three habitats were E1. Dry grasslands (136 taxa, 50.2\%), J1. Buildings of cities, towns and villages (31 taxa, 11.4\%) and E5.1 Anthropogenic herb stands (30 taxa, 11.1\%). The empty lands that emerged as a result of human interventions /affects, overgrazing and unconscious
Araştırma Makalesi

Makale Tarihçesi

Geliş Tarihi : 22.02 .2020

Kabul Tarihi : 01.05 .2020

Anahtar Kelimeler
Balıkesir,
Ekoloji
Flora
İstilacı tür
Yerli tür

Research Article

Article History

Received : 22.02 .2020

Accepted : 01.05.2020

Keywords

Balıkesir

Ecology

Flora

Invasive plant

Native plant 
in the region provided an opportunity to settle the invasive species in the meadows and pastures that are resistant to grazing. This situation led to the change of floristic composition, accordingly, decreased meadow and pasture quality, decreased of species richness and negatively affected agriculture. Therefore, the spreading areas of these species should be observed at certain time intervals and necessary measures should be taken. For this purpose, following the taxa has been identified, the situation must be reported to the stakeholders who are competent in this regard. Within the framework of emergency response for taxa that are considered important; Appropriate methods should be used to prevent spreading.

To Cite : Satıl F, Selvi S, Tümen G 2020. Balıkesir Florasında İstilacı Karaktere Sahip Yerli Bitki Taksonları Üzerine Bir Araştırma. KSÜ Tarım ve Doğa Derg 23 (4): 928-946. DOI: 10.18016/ksutarimdoga.vi.692964.

\section{GİRIŞ}

"Biyolojik İstila" canlının yaşadı̆̆ı doğal ortamda, orada olmayan başka bir canlı türü tarafından işgal edilerek ortamın doğal yapısının bozulması olarak tanımlanmaktadır (Gider, 2013). "İstilacı tür" ise doğal bitki örtüsüne önemli zararlar vererek ekosistemleri kolayca istila eden bitki türlerini tanımlamak için kullanılan bir kavramdır (Callaway ve Aschehoug, 2000; MacDougall ve Turkington, 2005). İstilac1 bitkiler; tolerans sınırlarının oldukça geniş olması, ortama uyum kabiliyetleri ve üreme potansiyellerinin oldukça yüksek olması gibi karakteristik özellikleri nedeni ile diğer türlere göre daha rekabetçidirler. Bu nedenle de yeni taşındıkları bölgelerde hızlı bir şekilde gelişir ve yayılarak alandaki diğer bütün bitki türlerine üstünlük sağlarlar (Önen, 2015; Kayaçetin, 2020). Aynı zamanda istilacı türler, önemli ekolojik ve çevre sorunlarına yol açarlar. Bu bitkiler yeni taşındıkları alanda; ekosistemin düzenini olumsuz etkiler, doğal bitki taksonlarının sayı ve yoğunluğunun azalmasına yol açarak ekosisteminin biyotik ve abiyotik çeşitliliğini olumsuz yönde etkilemektedirler (Richardson ve ark., 2000). Bugün ülkemiz içinde önemli bir çevre sorunu olan küresel iklim değişikliğinin de etkisiyle, istilacı türler bitki biyoçeşitliliğini de tehdit edecek boyuta ulaşmıştır.

Belirli bir coğrafik bölgenin doğal flora veya faunasında bulunmayıp belli bir amaç doğrultusunda kasten veya doğal yollarla dışarıdan taşınan canlılar da "Yabancı Tür" veya "Egzotik Tür" olarak tanımlanır (Önen, 2015).

Türkiye'nin farklı bölgelerinde yabancı istilacı türlerle ilgili birçok çalışma bulunmaktadır. Boz (2000) Aydın ili pamuk ekim alanlarındaki, Türe ve Köse (2000) ise Eskişehir ve çevresindeki bazı tarım alanlarında yayılış gösteren yabancı ot florası üzerinde çalışmalar yapmışlardır. Bunlara ek olarak, yabancı ve istilacı türlerin envanter çalışmasına yönelik; Yıldırım ve Ekim (2003) tarafindan Orta Anadolu Bölgesinde, Gider (2013) tarafından Aydın, Denizli, Muğla ve İzmir'deki tek yıllık otlaklarda ve yol kenarlarındaki istilacı türler, Sürmen ve ark. (2015) tarafından Samsun ili çayır ve mera alanlarındaki istilacı türlerin tespiti ile ilgili çalışmalar yapılmıştır. Ayrıca, Uygur ve ark. (2004), Eren (2010), Özkil ve Üremiş (2019) tarafından yapılmış sadece tür düzeyinde çalışmalar da bulunmaktadır. Karaer ve ark. (2015) da Türkiye'nin istilacı yabancı bitki biyoçeşitliliği, tehdit faktörleri ve alınması gerekli tedbirler üzerinde bir çalışma yapmıştır.

Bununla birlikte bazı kaynaklarda, yabancı otların yerli olabileceği gibi egzotik de olabileceği de bildirilmektedir (Uygur ve ark. 1984; Özer ve ark. 1999). Bugün yabancı ot olarak isimlendirilmiş, doğal sisteme negatif etkisi olmayan ancak müdahale edilmiş alanlarda ve tarım alanlarına yakın alanlarda yaşamaya uyum sağlamış istilacı olmayan ve tarıma önemli oranda zarar vermeyen türler de bulunmaktadır.

Son yıllarda yabancı istilacı tür kavramı ile birlikte yerli istilacı tür kavramı da tartışılmaya başlanmış ve yerli türlerin de istilacı olabileceğine dair bilimsel çalışmalar ortaya konmuştur (Valéry ve ark. 2009a; 2009b). Benzer şekilde, Valéry ve ark. (2008) da bir bölgeye yayılan yerli veya egzotik türlerin istilacı olarak adlandırılabileceğini, çünkü her iki durumda da aynı temel rekabet mekanizma, söz konusu olduğunu savunmaktadırlar.

Balıkesir ve çevresinde ne yabancı ne de yerli istilacı türler konusunda yapılmış bir çalışmaya rastlanılmamıştır. Bu çalışmada, doğal ortamları zorlanmadan işgal etme kabiliyetinde olan, komünite içerisinde insan müdahalesinin de etkisiyle hızla yayılan ve orada daha önce var olan diğer türlere üstünlük sağlayarak söz konusu ortamda baskın hale gelen yerli türler 'istilacı karaktere sahip yerli tür' olarak kabul edilmiştir. Bu kapsamda, Balıkesir florasındaki istilacı karaktere sahip yerli türlerin envanterini çıkartmak amacıyla il genelinde yapılan arazi çalışmalarına ek olarak daha önce çalışma ekibimizle yapılan foristik çalışmalarda (Doğan ve Özen, 1999; Dirmenci, 2006; Güner ve Akçiçek, 2013; Açar ve Satıl 2014; Tümen ve ark., 2018; Satıl ve ark., 2019a; 2019b) elde edilen veriler değerlendirilerek bölgede yayılış gösteren istilacı bitki taksonları belirlenmiş ve bu taksonların habitatlardaki dağılımı 
ve taşıdı̆̆ı ekolojik riskler ortaya konulmuştur.

\section{MATERYAL ve METOT}

Araştırmanın materyalini, 2016-2017 yılları arasında Orman ve Su İşleri Bakanlığ Parklar Genel Müdürlüğü tarafindan desteklenen ve Tümen ve ark. (Anonim, 2016) tarafindan gerçekleştirilen "Balıkesir İlinin Karasal ve İç Su Ekosistemleri Biyolojik Çeşitlilik Envanter ve İzleme Projesi” kapsamında toplanan bitki örnekleri oluşturmaktadır. Buna ek olarak, Balıkesir ve ilçelerinde daha önce çalışma ekibimizce yapılan floristik çalışmalarda (Doğan ve Özen, 1999; Dirmenci, 2006; Güner ve Akçiçek, 2013; Açar ve Satıl 2014; Tümen ve ark., 2018; Satıl ve ark., 2019a; 2019b) elde edilen veriler ve bitkiler de değerlendirilmiştir.

Çizelge 1' de bu çalışma noktalarının bulunduğu mevki ve koordinatları ile yükseltileri gösterilmiştir. Şekil 1' de ise Balıkesir ve ilçelerinde yürütülen arazi çalışmalarında 30 farklı çalışma noktası harita üzerinde işaretlenmiştir.

$\mathrm{Bu}$ kapsamda, Balıkesir ve ilçelerinin istilacı karaktere sahip yerli bitki taksonlarını tespit etmek amacıyla il genelinde, boş araziler, yol kenarları, sulak alanlar, kumul alanlar, çayır ve meralar gibi farklı habitatlarda dört mevsim floristik ve ekolojik gözlemler yapılarak istilacı bitki envanteri çıkartılmıştır (Çizelge 2).

Tespit edilen bitkilerin habitat sinıflandırması, EUNIS Habitat tipleri (Anonim, 2019) dikkate alınarak yapılmıştır. Bitki teşhislerinde, başta Flora of Turkey (Davis, 1965-85, 1988; Güner ve ark., 2000) olmak üzere "Mountain Flora of Greece", "Flora of Europae" ve alanda daha önceleri yapılmış floristik araştırmalardan faydalanılmıştır (Strid ve Tan, 1991; Tutin ve ark., 1964-1980). Bitkilerin Türkçe isimleri ise Güner ve ark. (2012)' a göre verilmiştir. İstilacı türlerin belirlenmesinde "İstilacı Bitkiler Kataloğu" (Önen, 2015) ve bu konuda kurulmuş olan ilgili data banklardan (Anonim, 2020a, 2020b) yararlanılmıştır.

Ayrıca, istilacı tür kategorisine giren çayır ve mera bitkileri ise "Türkiye'nin Çayır ve Mera Bitkileri" (Anonim, 2008) kaynağından kontrol edilmiştir. Teşhisi yapılan herbaryum örneklerine toplama numaraları verilmiş ve Balıkesir Üniversitesi Altınoluk Meslek Yüksekokulu Botanik Laboratuvarı' nda saklanmıştır.

Çizelge 1. Arazi çalışmalarının yürütüldüğü çalışma noktaları ve lokalite bilgileri

Table 1. Study points and field information where field studies are conducted

\begin{tabular}{|c|c|c|}
\hline Çalışma noktası (Study point) & İlçe (District) & Koordinat ve rakım (Coordinate and altitute) \\
\hline 1 nolu lokalite & Burhaniye & $39^{\circ} 25^{\prime} 48.03^{\prime \prime} \mathrm{K}, 26^{\circ} 53^{\prime} 3.76^{\prime \prime} \mathrm{D}, 166 \mathrm{~m}$ \\
\hline 2 nolu lokalite & Ayvalık & $39^{\circ} 21^{\prime} 23.75^{\prime \prime} \mathrm{K}, 26^{\circ} 44^{\prime} 47.42^{\prime \prime} \mathrm{D}, 50 \mathrm{~m}$ \\
\hline 3 nolu lokalite & Savaştepe & $39^{\circ} 26^{\prime} 30.37^{\prime \prime} \mathrm{K}, 27^{\circ} 39^{\prime} 6.63^{\prime \prime} \mathrm{D}, 457 \mathrm{~m}$ \\
\hline 4 nolu lokalite & İvrindi & $39^{\circ} 34^{\prime} 55.76^{\prime \prime} \mathrm{K}, 27^{\circ} 32^{\prime} 3.43^{\prime \prime} \mathrm{D}, 287 \mathrm{~m}$ \\
\hline 5 nolu lokalite & Havran & $39^{\circ} 36^{\prime} 42.25^{\prime \prime} \mathrm{K}, 27^{\circ} 3^{\prime} 37.81^{\prime \prime D}, 610 \mathrm{~m}$ \\
\hline 6 nolu lokalite & Merkez & $39^{\circ} 38^{\prime} 5.65^{\prime \prime} \mathrm{K}, 27^{\circ} 51^{\prime} 4.58^{\prime \prime} \mathrm{D}, 277 \mathrm{~m}$ \\
\hline 7 nolu lokalite & İvrindi & $39^{\circ} 30^{\prime} 16.54^{\prime \prime} \mathrm{K}, 27^{\circ} 21^{\prime} 25.54^{\prime \prime} \mathrm{D}, 287 \mathrm{~m}$ \\
\hline 8 nolu lokalite & Edremit & $39^{\circ} 38^{\prime} 7.97^{\prime \prime K}, 26^{\circ} 50^{\prime} 48.97 " \mathrm{D}, 376 \mathrm{~m}$ \\
\hline 9 nolu lokalite & Edremit & $39^{\circ} 35^{\prime} 17.31^{\prime \prime} \mathrm{K}, 26^{\circ} 46^{\prime} 47.33^{\prime \prime} \mathrm{D}, 17 \mathrm{~m}$ \\
\hline 10 nolu lokalite & Balya & $39^{\circ} 44^{\prime} 15.34^{\prime \prime} \mathrm{K}, 27^{\circ} 25^{\prime} 58.62^{\prime \prime} \mathrm{D}, 302 \mathrm{~m}$ \\
\hline 11 nolu lokalite & Merkez & $39^{\circ} 35^{\prime} 56.96^{\prime \prime} \mathrm{K}, 27^{\circ} 34^{\prime} 35.08^{\prime \prime} \mathrm{D}, 310 \mathrm{~m}$ \\
\hline 12 nolu lokalite & Sindirgi & $39^{\circ} 9^{\prime} 57.91^{\prime \prime K}, 27^{\circ} 57^{\prime} 39.98^{\prime \prime D}, 612 \mathrm{~m}$ \\
\hline 13 nolu lokalite & Sindırgı & $39^{\circ} 11^{\prime} 6.01^{\prime \prime} \mathrm{K}, 28^{\circ} 28^{\prime} 17.58^{\prime \prime} \mathrm{D}, 515 \mathrm{~m}$ \\
\hline 14 nolu lokalite & Kepsut & $39^{\circ} 40^{\prime} 16.32^{\prime \prime} \mathrm{K}, 28^{\circ} 4^{\prime} 37.40^{\prime \prime D}, 135 \mathrm{~m}$ \\
\hline 15 nolu lokalite & Merkez & $39^{\circ} 36^{\prime} 32.31^{\prime \prime K}, 27^{\circ} 53^{\prime} 36.12^{\prime \prime} \mathrm{D}, 120 \mathrm{~m}$ \\
\hline 16 nolu lokalite & Merkez & $39^{\circ} 37^{\prime} 28.86^{\prime \prime} \mathrm{K}, 27^{\circ} 54^{\prime} 46.99^{\prime \prime} \mathrm{D}, 130 \mathrm{~m}$ \\
\hline 17 nolu lokalite & Bigadiç & $39^{\circ} 24^{\prime} 49.49^{\prime \prime} \mathrm{K}, 28^{\circ} 17^{\prime} 39.84^{\prime \prime} \mathrm{D}, 396 \mathrm{~m}$ \\
\hline 18 nolu lokalite & Bigadiç & $39^{\circ} 37^{\prime} 7.44^{\prime \prime} \mathrm{K}, 28^{\circ} 20^{\prime} 51.11^{\prime \prime D}, 482 \mathrm{~m}$ \\
\hline 19 nolu lokalite & Dursunbey & $39^{\circ} 34^{\prime} 48.86^{\prime \prime} \mathrm{K}, 28^{\circ} 26^{\prime} 28.52^{\prime \prime} \mathrm{D}, 768 \mathrm{~m}$ \\
\hline 20 nolu lokalite & Dursunbey & $39^{\circ} 33^{\prime} 23.38^{\prime \prime} \mathrm{K}, 28^{\circ} 40^{\prime} 29.44^{\prime \prime} \mathrm{D}, 509 \mathrm{~m}$ \\
\hline 21 nolu lokalite & Merkez & $39^{\circ} 45^{\prime} 8.08^{\prime \prime} \mathrm{K}, 27^{\circ} 57^{\prime} 11.28^{\prime \prime} \mathrm{D}, 345 \mathrm{~m}$ \\
\hline 22 nolu lokalite & Susurluk & $39^{\circ} 49^{\prime} 18.85^{\prime \prime} \mathrm{K}, 28^{\circ} 6^{\prime} 18.98^{\prime \prime} \mathrm{D}, 310 \mathrm{~m}$ \\
\hline 23 nolu lokalite & Manyas & $39^{\circ} 58^{\prime} 35.82^{\prime \prime} \mathrm{K}, 28^{\circ} 1^{\prime} 7.61^{\prime \prime D}, 482 \mathrm{~m}$ \\
\hline 24 nolu lokalite & Susurluk & $39^{\circ} 57^{\prime} 3.28^{\prime \prime} \mathrm{K}, 28^{\circ} 4^{\prime} 46.94^{\prime \prime} \mathrm{D}, 251 \mathrm{~m}$ \\
\hline 25 nolu lokalite & Gönen & $39^{\circ} 59^{\prime} 46.57^{\prime \prime K}, 27^{\circ} 38^{\prime} 27.59^{\prime \prime} \mathrm{D}, 395 \mathrm{~m}$ \\
\hline 26 nolu lokalite & Gönen & $40^{\circ} 9^{\prime} 24.92^{\prime \prime} \mathrm{K}, 27^{\circ} 32^{\prime} 1.49^{\prime \prime} \mathrm{D}, 228 \mathrm{~m}$ \\
\hline 27 nolu lokalite & Gönen & $40^{\circ} 12^{\prime} 26.44^{\prime \prime} \mathrm{K}, 27^{\circ} 46^{\prime} 58.01^{\prime \prime} \mathrm{D}, 136 \mathrm{~m}$ \\
\hline 28 nolu lokalite & Gönen & $40^{\circ} 16^{\prime} 40.44^{\prime \prime} \mathrm{K}, 27^{\circ} 37^{\prime} 45.28^{\prime \prime} \mathrm{D}, 17 \mathrm{~m}$ \\
\hline 29 nolu lokalite & Bandırma & $40^{\circ} 21^{\prime} 40.47^{\prime \prime K}, 27^{\circ} 59^{\prime} 24.45^{\prime \prime D} 54 \mathrm{~m}$ \\
\hline 30 nolu lokalite & Erdek & $40^{\circ} 24^{\prime} 21.85^{\prime \prime} \mathrm{K}, 27^{\circ} 53^{\prime} 53.05^{\prime \prime} \mathrm{D}, 148 \mathrm{~m}$ \\
\hline
\end{tabular}




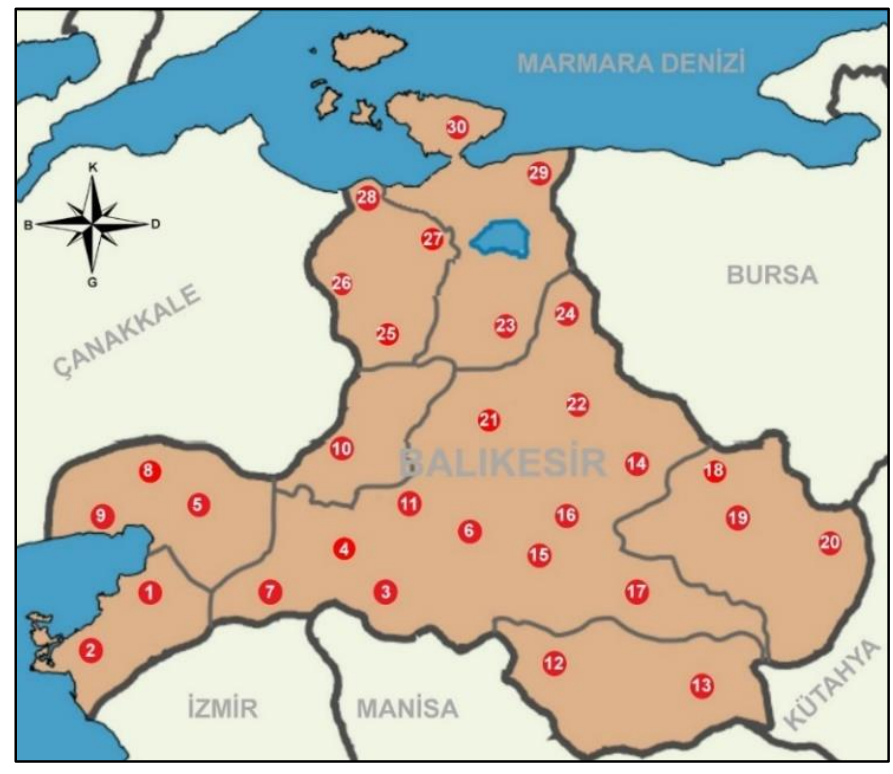

Şekil 1. Balıkesir il sınırlarında yürütülen çalışma noktaları

Figure 1. Study points carried out in the provincial border of Balıkesir

\section{BULGULAR}

Çalışma sonucunda Balıkesir florasında yayılış gösteren 44 familyaya ait 172 cins ve 271 bitki taksonunun istilacı karaktere sahip olduğu belirlenmiştir (Tablo 2). Bu istilacı yerli bitki türlerinin tamamı kapalı tohumlu bitki grubuna dahildir. Bunlar içerisinde en fazla takson içeren familyalar sirasiyla; Asteraceae (45 takson) Poaceae (38 takson) ve Fabaceae (33 takson) 'dir. En fazla takson içeren ilk üç cins ise; Trifolium (10 takson), Carex (6 takson) ve Juncus (6 takson)'dur. Taksonlarin habitat tiplerine göre dağılımında ise ilk üç habitat; E1. kuru otlaklar" (136 takson, \%50.2), "J1. şehir merkezleri, sürekli bina yapıları" (31takson, \%11.4), ve "E5.1 antropojenik bitki durumları" (30 takson, \%11.1) şeklindedir.

\section{SONUÇ ve TARTIŞMA}

Araştırma sonucunda; Balıkesir florasında toplam 271 takson'un istilacı karaktere sahip yerli bitkiler sınıfina dâhil edilebileceği görülmüştür. $\mathrm{Bu}$ yerli istilacı karaktere sahip bitkiler familya bazında ele alındığında Asteraceae'nin 45 taksonla (\%16.6) en büyük familya olduğu görülmektedir. Bu familyayı 38 taksonla Poaceae (\%14), 33 taksonla Fabaceae (\%12.2) ve 18 taksonla Apiaceae (\%6.6) familyaları takip etmektedir (Şekil 2A).

Çalışma alanında en çok yaygın olarak gözlenen iki familya Asteraceae ve Fabaceae'dir. Bu durumun nedenlerinden birisi, bu familyada diyasporlarin dağılımını kolaylaştıran özel mekanizmalara sahip olmasıdır. Ayrıca, bu familya üyelerinin ruderal stratejiyi benimsemiş olmaları, müdahale edilmiş ortamlarda kolayca topluluk oluşturarak hızla ortamı istila edebilme özelliklerinde olmaları da bu durumun muhtemel nedenlerindendir. Çünkü çalışma alanının yer aldığı bölgede istilacı türler için daha avantajlı hale geldiği antropojenik ve zoojenik etkiler oldukça fazladır. Gider (2013) tarafından Aydın, Denizli, Muğla ve İzmir'deki tek yıllık otlaklarda ve yol kenarlarında istilacı türler üzerine yapılan bir çalışma sonucuna göre; tespit edilen taksonların büyük bir çoğunluğu Poaceae (\%19) ve Fabaceae (\%17) familyalarına aittir. Aynı şekilde Yıldırım ve Ekim (2003) tarafindan yabancı ot florasını tespit etmek amaciyla Orta Anadolu Bölgesinde yürütülen çalışmada toplanan yabancı otlar, familyalara ait takson sayısına göre sinıflandırıldığında, en zengin familyanın Asteraceae olduğu ortaya çıkmıştır. Poaceae, Brassicaceae ve Fabaceae familyalarını ise Asteraceae'den sonra en zengin diğer familyalar olduğu belirtilmiştir. Ortaya çıkan bu veriler ile bizim çalışmalarımız sonucu elde ettiğimiz veriler benzerlik göstermektedir. Çalışma alanında en fazla takson içeren ilk üç cins; Trifolium (10 takson), Carex (6 takson) ve Juncus (6 takson)'dur (Şekil 2B). Her ne kadar bu örnekler yabancı istilacı türlerle ilgili olsa da Valéry ve ark. (2008), bir bölgeye yayılan yerli veya egzotik türlerin istilacı olarak adlandırılabileceğini, çünkü her iki durumda da aynı temel rekabet mekanizma, söz konusu olduğunu savunmaktadırlar.

Tespit edilen taksonların fitocoğrafik kompozisyonlarına göre dağılımları Şekil 3 ' te verilmiştir. Şekil 3 incelendiğinde taksonların \%66' sının fitocoğrafik elementi bilinmemektedir. Ancak bilinmeyen bu taksonların çoğunluğu ülkemizde kozmopolit olarak yayllı̧ göstermektedir. En fazla fitocoğrafik elementi içeren taksonlar \%23 ile Akdeniz elementi olup, onu \%8 ile Avrupa-Sibirya ve \%3 ile İran-Turan elementleri içermektedir.

Taksonlar EUNIS habitat tiplerine göre sinıflandırıldığında ilk üç habitat; "E1. kuru otlaklar" (136 takson, \%50.2), "J1. şehir merkezleri, sürekli bina yapıları" (31 takson, \%11.4), ve "E5.1 antropojenik bitki durumları" (30 takson, \%11.1) şeklindedir (Çizelge 3; Şekil 4).

Sonuçlardan da anlaşılacağı gibi istilacı karaktere sahip yerli türler en fazla otlak alanlar (çayır ve meralar, kuru otlarklar) ve şehir merkezlerinde (şehir içleri, yol kenarları, yıkık virane yerler) yoğunlaşmaktadır. Özellikle antropojenik etkiler sonucu bozulmuş boş alanlarda istilacı karaktere sahip yerli türler oldukça yaygındır.

Antropojenik müdahalelerle fiziksel ortamı değiştirip doğal komünitenin yapısını bozmanın, türlerin istila yeteneğini arttırdığını gösteren çok sayıda bilimsel çalışma vardır (Altman and Whitlatch, 2007; Lake and Leishman, 2004; Catford ve ark., 2012). Gider (2013)'in çalışmasında özellikle insan müdahalesinin olduğu otlaklarda Asteraceae ve Fabaceae taksonlarının daha 
Çizelge 2. Balıkesir florasındaki istilacı karaktere sahip yerli bitki taksonlar

Table 2. Native plant taxa with invasive character in Flora of Balıkesir

\begin{tabular}{|c|c|c|c|c|c|c|c|}
\hline No(No) & Familya (Family) & Takson (Taxon) & $\begin{array}{c}\text { Türkçe isim } \\
\text { (Turkish name) }\end{array}$ & Habitat tipi (Habitat type) & $\begin{array}{c}\text { EUNIS } \\
\text { Kodu } \\
(\text { EUNIS } \\
\text { Code) }\end{array}$ & $\begin{array}{c}\text { Fitocoğrafik element } \\
\text { (Phytogeographic } \\
\text { Element })\end{array}$ & $\begin{array}{l}\text { Toplayıcı no } \\
\text { (Collector no) }\end{array}$ \\
\hline 1 & Adoxaceae & Sambucus ebulus L. & Mürverotu & Kuru otlaklar & E1 & Bilinmiyor & SV 2247 \\
\hline 2 & Amaranthaceae & Amaranthus albus L. & Kömüş mancarı & Şehir merkezleri, sürekli bina yapıları & J1 & Bilinmiyor & SV 2433 \\
\hline 3 & Amaranthaceae & Atriplex hastata L. & Karapazı & Kıyı kumulları ve kumlu kıyıları & B1 & Bilinmiyor & SV 1694 \\
\hline 4 & Amaranthaceae & $\begin{array}{c}\text { Chenopodium album L. subsp. album } \\
\text { var. album }\end{array}$ & Aksirken & Şehir merkezleri, sürekli bina yapıları & J1 & Bilinmiyor & SV 2253 \\
\hline 5 & Amaranthaceae & Chenopodium botrys L. & Kızılbacak & Antropojenik bitki durumları & E5.1 & Bilinmiyor & SV 1751 \\
\hline 6 & Apiaceae & Ammi majus L. & Kürdanotu & Şehir merkezleri, sürekli bina yapıları & $\mathrm{J} 1$ & Akdeniz & SV 1752 \\
\hline 7 & Apiaceae & Ammi visnaga (L.) Lam. & Hiltan & $\begin{array}{l}\text { Bitki Örtüsünün Olmadı̆̆ı ya da } \\
\text { Seyrek Bitki Örtülü Alanlar }\end{array}$ & C3.6 & Akdeniz & SV 2103 \\
\hline 8 & Apiaceae & $\begin{array}{l}\text { Anthriscus nemorosa (M.Bieb.) } \\
\text { Spreng. }\end{array}$ & Peçek & Kuru otlaklar & E1 & Bilinmiyor & SV 2150 \\
\hline 9 & Apiaceae & Apium nodiflorum (L.) Lag. & Bendik & $\begin{array}{l}\text { Bitki Örtüsünün Olmadığı ya da } \\
\text { Seyrek Bitki Örtülü Alanlar }\end{array}$ & C3.6 & Bilinmiyor & SV 2152 \\
\hline 10 & Apiaceae & Bupleurum odontites L. & Damarlı şeytanayağı & Sulanmayan karışık tarım alanları & $\mathrm{I} 2$ & Bilinmiyor & SV 2435 \\
\hline 11 & Apiaceae & Conium maculatum $\mathrm{L}$. & Baldiran & Antropojenik bitki durumları & E5.1 & Bilinmiyor & SV 2427 \\
\hline 12 & Apiaceae & Daucus broteri Ten. & Çocukboğanotu & Kıyı kumulları ve kumlu kıyıları & $\mathrm{B} 1$ & Akdeniz & SV 1901 \\
\hline 13 & Apiaceae & $\begin{array}{l}\text { Echinophora tenuifolia L. subsp. } \\
\text { sibthorpiana (Guss.) Tutin }\end{array}$ & Sarıçördük & $\begin{array}{c}\text { Nadasa birakılmıs sulanmayan } \\
\text { alanlar }\end{array}$ & $\mathrm{I} 1.5$ & İran-Turan & SV 2104 \\
\hline 14 & Apiaceae & Eryngium bithynicum Boiss. & Çakırotu & Sulanmayan karışık tarım alanları & $\mathrm{I} 2$ & İran-Turan & SV 2436 \\
\hline 15 & Apiaceae & $\begin{array}{l}\text { Eryngium campestre L. subsp. } \\
\text { campestre }\end{array}$ & Kırsenet & Sulanmayan karışık tarım alanları & $\mathrm{I} 2$ & Bilinmiyor & SV 1807 \\
\hline 16 & Apiaceae & $\begin{array}{c}\text { Eryngium campestre L. var. virens } \\
\text { Link }\end{array}$ & Yerkestanesi & Sulanmayan karışık tarım alanları & $\mathrm{I} 2$ & Bilinmiyor & SV 2282 \\
\hline 17 & Apiaceae & Foeniculum vulgare Mill. & Rezene & Şehir merkezleri, sürekli bina yapıları & J1 & Bilinmiyor & SV 1654 \\
\hline 18 & Apiaceae & Lagoecia cuminoides L. & Pülüskün & Kuru otlaklar & E1 & Akdeniz & SV 2472 \\
\hline 19 & Apiaceae & Opopanax hispidus (Friv.) Griseb & Kaymacık & Kuru otlaklar & E1 & Bilinmiyor & SV 2105 \\
\hline 20 & Apiaceae & Orlaya daucoides (L.) Greuter & Dilkanatan & Kıyı kumulları ve kumlu kıyıları & B1 & Akdeniz & SV 1897 \\
\hline 21 & Apiaceae & Scandix pecten-veneris $\mathrm{L}$. & Zühretarağı & Kuru otlaklar & E1 & Bilinmiyor & SV 2277 \\
\hline 22 & Apiaceae & Tordylium apulum L. & Kafkalida & Kuru otlaklar & E1 & Akdeniz & SV 1840 \\
\hline 23 & Apiaceae & $\begin{array}{c}\text { Torilis arvensis (Huds.) Link subsp. } \\
\text { arvensis }\end{array}$ & Dercikotu & Sulanmayan karışık tarım alanları & $\mathrm{I} 2$ & Bilinmiyor & SV 2106 \\
\hline 24 & Apocynaceae & Cionura erecta (L.) Griseb. & Babrik & Kıyı kumulları ve kumlu kıyıları & B1 & Akdeniz & SV 2422 \\
\hline 25 & Apocynaceae & Cynanchum acutum L. subsp. acutum & Bacirgan & Kıyı kumulları ve kumlu kıyıları & B1 & Bilinmiyor & SV 2423 \\
\hline 26 & Araliaceae & Hedera helix L. f. helix & Duvar sarmaşı̆̆ı & Sulanmayan karışık tarım alanları & $\mathrm{I} 2$ & Bilinmiyor & SV 1934 \\
\hline 27 & Asteraceae & $\begin{array}{c}\text { Anthemis cretica L. subsp. } \\
\text { leucanthemoides (Boiss.) Grierson }\end{array}$ & Akbabaçça & Antropojenik bitki durumları & E5.1 & Bilinmiyor & SV 2250 \\
\hline 28 & Asteraceae & Artemisia vulgaris $\mathrm{L}$. & Kabayavşan & Antropojenik bitki durumları & E5.1 & Bilinmiyor & SV 1696 \\
\hline 29 & Asteraceae & Bellis annua L. & Akbubeçlik & Kuru otlaklar & E1 & Akdeniz & SV 2108 \\
\hline 30 & Asteraceae & Bellis perennis $\mathrm{L}$. & Koyungözü & Kuru otlaklar & E1 & Avrupa-Sibirya & SV 2109 \\
\hline
\end{tabular}




\begin{tabular}{|c|c|c|c|c|c|c|c|}
\hline 31 & Asteraceae & Bellis sylvestris Cirillo & Nineotu & Kuru otlaklar & E1 & Akdeniz & SV 2110 \\
\hline 32 & Asteraceae & Calendula arvensis (Vaill.) L. & Portakal nergisi & Antropojenik bitki durumları & E1 & Bilinmiyor & SV 2437 \\
\hline 33 & Asteraceae & Cardopatium corymbosum (L.) Pers. & Kurtludiken & $\begin{array}{c}\text { Nadasa bırakılmış sulanmayan } \\
\text { alanlar }\end{array}$ & $\mathrm{I} 1.5$ & Akdeniz & SV 1754 \\
\hline 34 & Asteraceae & $\begin{array}{l}\text { Carduus pycnocephalus L. subsp. } \\
\text { albidus (M.Bieb.) Kazmi }\end{array}$ & Eşeksoymacı & $\begin{array}{c}\text { Nadasa bırakılmış sulanmayan } \\
\text { alanlar }\end{array}$ & $\mathrm{I} 1.5$ & Bilinmiyor & SV 2486 \\
\hline 35 & Asteraceae & Carlina corymbosa L. & Kırkbaş dikeni & Şehir merkezleri, sürekli bina yapıları & J1 & Akdeniz & SV 1833 \\
\hline 36 & Asteraceae & Carthamus dentatus (Forssk.) Vahl & Kınadikeni & Antropojenik bitki durumları & E5.1 & Bilinmiyor & SV 2478 \\
\hline 37 & Asteraceae & Carthamus lanatus $\mathrm{L}$. & Sarıdiken & Antropojenik bitki durumları & E5.1 & Bilinmiyor & SV 1633 \\
\hline 38 & Asteraceae & Centaurea iberica Trev. ex Sprengel & Deligöz dikeni & Antropojenik bitki durumları & E5.1 & Bilinmiyor & SV 2492 \\
\hline 39 & Asteraceae & $\begin{array}{c}\text { Centaurea solstitialis L. subsp. } \\
\text { solstitialis }\end{array}$ & Çakırdikeni & Antropojenik bitki durumları & E5.1 & Bilinmiyor & SV 1964 \\
\hline 40 & Asteraceae & Centaurea spinosa L. var. spinosa & Denizgeveni & Kıyı kumulları ve kumlu kıyıları & B1 & Bilinmiyor & SV 2439 \\
\hline 41 & Asteraceae & Centaurea virgata Lam. & Acısüpürge & Sulanmayan karışık tarım alanları & $\mathrm{I} 2$ & İran-Turan & SV 2246 \\
\hline 42 & Asteraceae & Cichorium intybus $\mathrm{L}$. & Hindiba & $\begin{array}{c}\text { Nadasa birakılmışs sulanmayan } \\
\text { alanlar }\end{array}$ & $\mathrm{I} 1.5$ & Bilinmiyor & SV 1699 \\
\hline 43 & Asteraceae & Cirsium arvense (L.) Scop. & Köygöçüren & Antropojenik bitki durumları & E5.1 & Bilinmiyor & SV 1806 \\
\hline 44 & Asteraceae & $\begin{array}{l}\text { Cirsium creticum d Urv. subsp. } \\
\text { creticum }\end{array}$ & Eşekçalısı & $\begin{array}{c}\text { Büyük şehirlerin kenarında kalan } \\
\text { alanlar }\end{array}$ & $\mathrm{J} 2$ & Akdeniz & SV 2242 \\
\hline 45 & Asteraceae & Conyza bonariensis (L.) Cronquist & Çakalotu & Antropojenik bitki durumları & E5.1 & Bilinmiyor & SV 1755 \\
\hline 46 & Asteraceae & Conyza canadensis (L.) Cronquist & Selviotu & Antropojenik bitki durumları & E5.1 & Bilinmiyor & SV 1629 \\
\hline 47 & Asteraceae & $\begin{array}{c}\text { Cota tinctoria (L.) J.Gay ex Guss. var. } \\
\text { tinctoria }\end{array}$ & Boyacı papatyası & Antropojenik bitki durumları & E5.1 & Bilinmiyor & SV 1756 \\
\hline 48 & Asteraceae & $\begin{array}{c}\text { Crepis foetida L. } \\
\text { subsp. rhoeadifolia (M.Bieb.) Čelak. }\end{array}$ & Kohum & $\begin{array}{l}\text { Bitki Örtüsünün Olmadığı ya da } \\
\text { Seyrek Bitki Örtülü Alanlar }\end{array}$ & C3.6 & Bilinmiyor & SV 2477 \\
\hline 49 & Asteraceae & $\begin{array}{l}\text { Crepis sancta (L.) Bornm. subsp. } \\
\text { obovata (Boiss. \& Noë) Babc. }\end{array}$ & Yabankıskısı & Şehir merkezleri, sürekli bina yapıları & J1 & Bilinmiyor & SV 2288 \\
\hline 50 & Asteraceae & Crupina crupinastrum (Moris) Vis. & Gelindöndüren & Kuru otlaklar & $\mathrm{E} 1$ & Bilinmiyor & SV 1883 \\
\hline 51 & Asteraceae & Echinops microcephalus $\mathrm{Sm}$. & Papaz kalpağı & $\begin{array}{l}\text { Nadasa bırakılmış sulanmayan } \\
\text { alanlar }\end{array}$ & $\mathrm{I} 1.5$ & Akdeniz & SV 1658 \\
\hline 52 & Asteraceae & Echinops ritro L. & Topuz & $\begin{array}{l}\text { Bitki Örtüsünün Olmadı̆̆ı ya da } \\
\text { Seyrek Bitki Örtülü Alanlar }\end{array}$ & C3.6 & Bilinmiyor & SV 2295 \\
\hline 53 & Asteraceae & Filago pyramidata L. & Ateşpamuğu & Kuru otlaklar & $\mathrm{E} 1$ & Bilinmiyor & SV 2257 \\
\hline 54 & Asteraceae & Inula graveolens (L.) Desf. & Deli sarıot & Kuru otlaklar & E1 & Akdeniz & SV 2266 \\
\hline 55 & Asteraceae & Inula viscosa (L.) Aiton & Sümenit & $\begin{array}{l}\text { Büyük şehirlerin kenarında kalan } \\
\text { alanlar }\end{array}$ & J2 & Akdeniz & SV 1624 \\
\hline 56 & Asteraceae & Lactuca serriola L. & Eşekhelvası & Şehir merkezleri, sürekli bina yapıları & J1 & Bilinmiyor & SV 1887 \\
\hline 57 & Asteraceae & $\begin{array}{l}\text { Lapsana communis L. subsp. } \\
\text { intermedia (M.Bieb.) Hayek }\end{array}$ & Deli şebrek & Kuru otlaklar & E1 & Bilinmiyor & SV 2442 \\
\hline 58 & Asteraceae & Notobasis syriaca (L.) Cass. & Yavan kenger & Kuru otlaklar & E1 & Akdeniz & SV 2286 \\
\hline 59 & Asteraceae & Picnomon acarna (L.) Cass. & Kılçıkdiken & Kuru otlaklar & E1 & Akdeniz & SV 1811 \\
\hline 60 & Asteraceae & $\begin{array}{l}\text { Pilosella piloselloides (Vill.) Soják } \\
\text { subsp. magyarica S.Bräut. \& Greuter }\end{array}$ & Daztırnakotu & Kuru otlaklar & E1 & Bilinmiyor & SV 1757 \\
\hline 61 & Asteraceae & $\begin{array}{c}\text { Scolymus hispanicus L. subsp. } \\
\text { hispanicus }\end{array}$ & Şevketi bostan & Kuru otlaklar & E1 & Akdeniz & SV 1622 \\
\hline
\end{tabular}




\begin{tabular}{|c|c|c|c|c|c|c|c|}
\hline 62 & Asteraceae & $\begin{array}{c}\text { Scorzonera laciniata L. subsp. } \\
\text { laciniata }\end{array}$ & Parım & Kuru otlaklar & E1 & Bilinmiyor & SV 1657 \\
\hline 63 & Asteraceae & Senecio vernalis Waldst. \& Kit. & Kanaryaotu & Kıyı kumulları ve kumlu kıyıları & B1 & Bilinmiyor & SV 1692 \\
\hline 64 & Asteraceae & $\begin{array}{c}\text { Silybum marianum }(\mathrm{L} .) \text { Gaertn subsp. } \\
\text { marianum }\end{array}$ & Devedikeni & Şehir merkezleri, sürekli bina yapıları & J1 & Akdeniz & SV 1758 \\
\hline 65 & Asteraceae & $\begin{array}{c}\text { Solidago virgaurea L. subsp. } \\
\text { virgaurea }\end{array}$ & Altınbaşak çiçeği & Şehir merkezleri, sürekli bina yapıları & $\mathrm{J} 1$ & Avrupa-Sibirya & SV 2255 \\
\hline 66 & Asteraceae & $\begin{array}{l}\text { Sonchus asper }(\text { L.) Hill. subsp. } \\
\text { glaucescens (Jord.) Ball }\end{array}$ & Eşekgevreği & Şehir merkezleri, sürekli bina yapıları & $\mathrm{J} 1$ & Bilinmiyor & SV 2274 \\
\hline 67 & Asteraceae & $\begin{array}{l}\text { Tragopogon porrifolius subsp. } \\
\text { eriospermus (Ten.) Greuter }\end{array}$ & Boduryemlik & Kuru otlaklar & E1 & Akdeniz & SV 2153 \\
\hline 68 & Asteraceae & $\begin{array}{l}\text { Tragopogon porrifolius L. subsp. } \\
\text { longirostris (Sch.Bip.) Greuter }\end{array}$ & Helevan & Sulanmayan karışık tarım alanları & $\mathrm{I} 2$ & Bilinmiyor & SV 2154 \\
\hline 69 & Asteraceae & Xanthium spinosum L. & Pitrak & Şehir merkezleri, sürekli bina yapıları & J1 & Bilinmiyor & SV 2262 \\
\hline 70 & Asteraceae & $\begin{array}{c}\text { Xanthium strumarium L. subsp. } \\
\text { strumarium }\end{array}$ & Koca pitrak & Şehir merkezleri, sürekli bina yapıları & J1 & Bilinmiyor & SV 2261 \\
\hline 71 & Asteraceae & Xeranthemum annuum L. & Kağıtçiçeği & Şehir merkezleri, sürekli bina yapıları & $\mathrm{J} 1$ & Bilinmiyor & SV 2260 \\
\hline 72 & Boraginaceae & Anchusa azurea Mill. subsp. azurea & Sığırdili & Antropojenik bitki durumları & E5.1 & Bilinmiyor & SV 2443 \\
\hline 73 & Boraginaceae & Anchusa hybrida Ten. & Tatlibaba & Antropojenik bitki durumları & E5.1 & Akdeniz & SV 2465 \\
\hline 74 & Boraginaceae & Anchusa officinalis L. & Ballağan & Sulanmayan karışık tarım alanları & I2 & Avrupa-Sibirya & SV 2428 \\
\hline 75 & Boraginaceae & Cynoglossum creticum Mill. & Pisiktetiği & Kuru otlaklar & E1 & Bilinmiyor & SV 2160 \\
\hline 76 & Boraginaceae & Cynoglossum montanum $\mathrm{L}$. & Dağ köpekdili & Kuru otlaklar & E1 & Avrupa-Sibirya & SV 2161 \\
\hline 77 & Boraginaceae & Echium angustifolium Mill. & Agres & Sulanmayan karışık tarım alanları & $\mathrm{I} 2$ & Akdeniz & SV 2167 \\
\hline 78 & Boraginaceae & Echium italicum L. & Kurtkuyruğu & Şehir merkezleri, sürekli bina yapıları & $\mathrm{J} 1$ & Akdeniz & SV 2168 \\
\hline 79 & Boraginaceae & Echium plantagineum L. & Kırkbatıran & Sulanmayan karışık tarım alanları & I2 & Akdeniz & SV 2170 \\
\hline 80 & Boraginaceae & Echium vulgare L.subsp. vulgare & Engerek otu & Kuru otlaklar & E1 & Avrupa-Sibirya & SV 2180 \\
\hline 81 & Boraginaceae & Heliotropium europaeum L. & Akrepotu & Şehir merkezleri, sürekli bina yapıları & J1 & İran-Turan & SV 2252 \\
\hline 82 & Boraginaceae & Lithospermum arvense $\mathrm{L}$. & Taşkesen & Kuru otlaklar & E1 & Avrupa-Sibirya & SV 2466 \\
\hline 83 & Boraginaceae & $\begin{array}{l}\text { Myosotis alpestris F.W.Schmidt } \\
\text { subsp. alpestris }\end{array}$ & Boncukotu & Kuru otlaklar & E1 & Bilinmiyor & SV 1916 \\
\hline 84 & Boraginaceae & $\begin{array}{c}\text { Myosotis arvensis }(\mathrm{L} .) \text { Hill. subsp. } \\
\text { arvensis }\end{array}$ & Kardeşboncuğu & Kuru otlaklar & E1 & Avrupa-Sibirya & SV 2444 \\
\hline 85 & Boraginaceae & Onosma heterophylla Griseb. & Deli emzik & Kuru otlaklar & E1 & Avrupa-Sibirya & SV 1930 \\
\hline 86 & Brassicaceae & $\begin{array}{c}\text { Alyssoides utriculata (L.) Medik. var. } \\
\text { utriculata }\end{array}$ & Deli kuduzotu & $\begin{array}{c}\text { Nadasa bırakılmıs sulanmayan } \\
\text { alanlar }\end{array}$ & $\mathrm{I} 1.5$ & Bilinmiyor & SV 1759 \\
\hline 87 & Brassicaceae & Calepina irregularis (Asso) Thell. & Top hardal & Şehir merkezleri, sürekli bina yapıları & $\mathrm{J} 1$ & Bilinmiyor & SV 2298 \\
\hline 88 & Brassicaceae & Capsella bursa-pastoris (L.) Medik. & Çobançantası & Antropojenik bitki durumları & E5.1 & Bilinmiyor & SV 2499 \\
\hline 89 & Brassicaceae & $\begin{array}{l}\text { Descurainia sophia (L.) Webb ex } \\
\text { Prantl subsp. sophia }\end{array}$ & Sadırotu & Antropojenik bitki durumları & E5.1 & Bilinmiyor & SV 1653 \\
\hline 90 & Brassicaceae & Diplotaxis tenuifolia (L.) DC & Türpenk & Antropojenik bitki durumları & E5.1 & Bilinmiyor & SV 2293 \\
\hline 91 & Brassicaceae & Draba verna L. & Çırçırotu & Antropojenik bitki durumları & E5.1 & Bilinmiyor & SV 1905 \\
\hline 92 & Brassicaceae & Lepidium campestre (L.) Aiton & Horozcuk & Kuru otlaklar & E1 & Bilinmiyor & SV 2482 \\
\hline 93 & Brassicaceae & Lepidium draba L. & Diğnik & Şehir merkezleri, sürekli bina yapıları & J1 & Bilinmiyor & SV 1760 \\
\hline 94 & Brassicaceae & Lepidium latifolium $\mathrm{L}$. & Nujdar & Kuru otlaklar & E1 & Bilinmiyor & SV 2474 \\
\hline 95 & Brassicaceae & Nasturtium officinale R.Br., Aiton & Suteresi & Kuru otlaklar & E1 & Bilinmiyor & SV 2468 \\
\hline
\end{tabular}




\begin{tabular}{|c|c|c|c|c|c|c|c|}
\hline 96 & Brassicaceae & $\begin{array}{c}\text { Raphanus raphanistrum L. subsp. } \\
\text { raphanistrum }\end{array}$ & Eşek turpu & $\begin{array}{c}\text { Nadasa birakılmıs sulanmayan } \\
\text { alanlar }\end{array}$ & $\mathrm{I} 1.5$ & Bilinmiyor & SV 1849 \\
\hline 97 & Brassicaceae & Sinapis alba L. subsp. alba & Mamanık & Şehir merkezleri, sürekli bina yapıları & J1 & Bilinmiyor & SV 1899 \\
\hline 98 & Campanulaceae & Legousia pentagonia (L.) Thell. & Kadınaynası & Kuru otlaklar & E1 & Akdeniz & SV 2445 \\
\hline 99 & Capparaceae & Capparis spinosa L. & Kebere & $\begin{array}{l}\text { Bitki Örtüsünün Olmadiğı ya da } \\
\text { Seyrek Bitki Örtülü Alanlar }\end{array}$ & C3.6 & Bilinmiyor & SV 1835 \\
\hline 100 & Caprifoliaceae & Dipsacus laciniatus L. & Fesçitarağ & Antropojenik bitki durumları & E5.1 & Bilinmiyor & SV 1886 \\
\hline 101 & Caprifoliaceae & Knautia orientalis L. & Eşekkulağı & Kuru otlaklar & E1 & Akdeniz & SV 1848 \\
\hline 102 & Caprifoliaceae & Scabiosa atropurpurea L. & Mor uyuzotu & Kuru otlaklar & E1 & Bilinmiyor & SV 1675 \\
\hline 103 & Caprifoliaceae & $\begin{array}{l}\text { Scabiosa columbaria L. subsp. } \\
\text { ochroleuca (L.) Čélak }\end{array}$ & Sarı uyuzotu & Kuru otlaklar & E1 & Bilinmiyor & SV 1634 \\
\hline 104 & Caprifoliaceae & Valeriana dioscoridis $\mathrm{Sm}$. & Çobanzurnası & Kuru otlaklar & E1 & Akdeniz & SV 2270 \\
\hline 105 & Caryophyllaceae & Agrostemma githago L. & Buğday karamuğu & $\begin{array}{l}\text { Bitki Örtüsünün Olmadı̆̆ı ya da } \\
\text { Seyrek Bitki Örtülü Alanlar }\end{array}$ & C3.6 & Bilinmiyor & SV 1910 \\
\hline 106 & Caryophyllaceae & Herniaria hirsuta L. & Deli yaran & Kuru otlaklar & E1 & Bilinmiyor & SV 1761 \\
\hline 107 & Caryophyllaceae & Herniaria incana Lam. & Kaba yaran & Kuru otlaklar & E1 & Bilinmiyor & SV 1697 \\
\hline 108 & Caryophyllaceae & $\begin{array}{c}\text { Minuartia hybrida (Vill.) Schischk. } \\
\text { subsp. hybrida }\end{array}$ & Çayır tıstısı & Kuru otlaklar & E5.1 & Bilinmiyor & SV 1960 \\
\hline 109 & Caryophyllaceae & $\begin{array}{l}\text { Scleranthus annuus L. subsp. } \\
\text { verticillatus (Tausch) Arcang. }\end{array}$ & Zar kınavel & Kuru otlaklar & E1 & Bilinmiyor & SV 2281 \\
\hline 110 & Caryophyllaceae & Stellaria media (L.) Vill. & Kuşotu & Şehir merkezleri, sürekli bina yapıları & $\mathrm{J} 1$ & Bilinmiyor & SV 1805 \\
\hline 111 & Convolvulaceae & Convolvulus arvensis L. & Tarla sarmaşı̆̆ & $\begin{array}{l}\text { Bitki Örtüsünün Olmadiğı ya da } \\
\text { Seyrek Bitki Örtülü Alanlar }\end{array}$ & C3.6 & Bilinmiyor & SV 1620 \\
\hline 112 & Convolvulaceae & $\begin{array}{c}\text { Convolvulus betonicifolius Mill. subsp. } \\
\text { betonicifolius }\end{array}$ & Büyükyayılgan & Sulanmayan karışık tarım alanları & $\mathrm{I} 2$ & Akdeniz & SV 2036 \\
\hline 113 & Convolvulaceae & Convolvulus cantabrica L. & Çadırçiçeği & Antropojenik bitki durumları & E5.1 & Akdeniz & SV 2446 \\
\hline 114 & Convolvulaceae & Convolvulus scammonia $\mathrm{L}$. & Bingözotu & Antropojenik bitki durumları & E5.1 & Akdeniz & SV 2038 \\
\hline 115 & Convolvulaceae & Cuscuta campestris Yunck. & Kâfirsaçı & Kuru otlaklar & E1 & Bilinmiyor & SV 1762 \\
\hline 116 & Convolvulaceae & $\begin{array}{l}\text { Cuscuta monogyna Vahl. subsp. } \\
\text { esquamata (Engelm.) Plitman }\end{array}$ & Som kızılkurtotu & Kuru otlaklar & E1 & Bilinmiyor & SV 1626 \\
\hline 117 & Cucurbitaceae & Ecballium elaterium (L.) A.Rich. & Eşek hıyarı & Antropojenik bitki durumları & E5.1 & Akdeniz & SV 1888 \\
\hline 118 & Cyperaceae & $\begin{array}{l}\text { Carex cuprina (Sándor ex Heuff.) } \\
\text { Nendtv. ex A.Kern. }\end{array}$ & Kurusaz & $\begin{array}{c}\text { Yüzey suyu olmayan sazlıklar, kamış } \\
\text { yatakları }\end{array}$ & D5 & Bilinmiyor & SV 2244 \\
\hline 119 & Cyperaceae & Carex distachya Desf. var. distachya & İkiz ayakotu & $\begin{array}{c}\text { Yüzey suyu olmayan sazlıklar, kamış } \\
\text { yatakları }\end{array}$ & D5 & Bilinmiyor & SV 2500 \\
\hline 120 & Cyperaceae & Carex distans L. subsp. distans & Sina ayakotu & $\begin{array}{c}\text { Yüzey suyu olmayan sazlıklar, kamış } \\
\text { yatakları }\end{array}$ & D5 & Akdeniz & SV 2050 \\
\hline 121 & Cyperaceae & Carex divisa Huds. & Zevzirçimeni & $\begin{array}{c}\text { Yüzey suyu olmayan sazlıklar, kamış } \\
\text { yatakları }\end{array}$ & D5 & Bilinmiyor & SV 2278 \\
\hline 122 & Cyperaceae & Carex divulsa Stokes & Ayakotu & $\begin{array}{c}\text { Yüzey suyu olmayan sazlıklar, kamış } \\
\text { yatakları }\end{array}$ & D5 & Bilinmiyor & SV 2420 \\
\hline 123 & Cyperaceae & $\begin{array}{l}\text { Carex flacca Schreb. subsp. } \\
\text { erythrostachys (Hoppe) Holub }\end{array}$ & Yanık çayırsazı & $\begin{array}{c}\text { Yüzey suyu olmayan sazlıklar, kamış } \\
\text { yatakları }\end{array}$ & D5 & Akdeniz & SV 2287 \\
\hline 124 & Equisetaceae & Equisetum arvense L. & Atkuyruğu & $\begin{array}{c}\text { Kalıcı oligotrofik göller, göletler ve } \\
\text { havuzlar }\end{array}$ & C1.1 & Bilinmiyor & SV 2258 \\
\hline
\end{tabular}




\begin{tabular}{|c|c|c|c|c|c|c|c|}
\hline 125 & Equisetaceae & Equisetum palustre $\mathrm{L}$. & Kırkbacak & $\begin{array}{l}\text { Kalıcı oligotrofik göller, göletler ve } \\
\text { havuzlar }\end{array}$ & C1.1 & Bilinmiyor & SV 2447 \\
\hline 126 & Euphorbiaceae & Chrozophora tinctoria (L.) A.Juss. & Siğilotu & Antropojenik bitki durumları & E5.1 & Bilinmiyor & SV 2470 \\
\hline 127 & Euphorbiaceae & Euphorbia aleppica L. & Haşul & Kuru otlaklar & E1 & Bilinmiyor & SV 2484 \\
\hline 128 & Euphorbiaceae & $\begin{array}{c}\text { Euphorbia amygdaloides L. subsp. } \\
\text { amygdaloides }\end{array}$ & Zerana & Kuru otlaklar & E1 & Avrupa-Sibirya & SV 2279 \\
\hline 129 & Euphorbiaceae & $\begin{array}{c}\text { Euphorbia helioscopia L. subsp. } \\
\text { helioscopia }\end{array}$ & Feribanotu & Şehir merkezleri, sürekli bina yapıları & J1 & Bilinmiyor & SV 1950 \\
\hline 130 & Euphorbiaceae & Euphorbia peplus L. & Bahçe sütleğeni & $\begin{array}{l}\text { Büyük şehirlerin kenarında kalan } \\
\text { alanlar }\end{array}$ & J2 & Bilinmiyor & SV 2425 \\
\hline 131 & Euphorbiaceae & Mercurialis annua L. & Parşen & Kuru otlaklar & E1 & Bilinmiyor & SV 1656 \\
\hline 132 & Fabaceae & Bituminaria bituminosa (L.) C.H.Stirt & Asfalt otu & Antropojenik bitki durumları & E5.1 & Akdeniz & SV 2256 \\
\hline 133 & Fabaceae & Cicer montbretii Jaub. \& Spach. & Deli nohut & Sulanmayan karısılk tarım alanları & $\mathrm{I} 2$ & Akdeniz & SV 1764 \\
\hline 134 & Fabaceae & Coronilla scorpioides (L.) W.D.J.Koch & Akrep burçağ & Sulanmayan karışı tarım alanları & I2 & Bilinmiyor & SV 2251 \\
\hline 135 & Fabaceae & Hymenocarpos circinnatus (L.) Savi & Pulluot & Kuru otlaklar & E1 & Bilinmiyor & SV 1655 \\
\hline 136 & Fabaceae & Lathyrus annuus L. & Dağdırılcası & Kuru otlaklar & E1 & Akdeniz & SV 2497 \\
\hline 137 & Fabaceae & Lathyrus cicera L. & Colpan & Kuru otlaklar & E1 & Akdeniz & SV 2030 \\
\hline 138 & Fabaceae & $\begin{array}{l}\text { Lathyrus laxiflorus (Desf.) O.Kuntze } \\
\text { subsp. laxiflorus }\end{array}$ & Deliburçak & Kuru otlaklar & E1 & Bilinmiyor & SV 1894 \\
\hline 139 & Fabaceae & Lathyrus sativus L. & Mürdümük & Kuru otlaklar & E1 & Akdeniz & SV 1674 \\
\hline 140 & Fabaceae & $\begin{array}{l}\text { Lotus corniculatus } \mathrm{L} \text {. var. } \\
\text { corniculatus }\end{array}$ & Gazalboynuzu & Kuru otlaklar & E1 & Bilinmiyor & SV 1949 \\
\hline 141 & Fabaceae & Medicago orbicularis (L.) Bartal. & Paralık & Kuru otlaklar & E1 & Bilinmiyor & SV 2185 \\
\hline 142 & Fabaceae & $\begin{array}{l}\text { Medicago polymorpha L. var. } \\
\text { polymorpha }\end{array}$ & Kırkyonca & Kuru otlaklar & E1 & Bilinmiyor & SV 1808 \\
\hline 143 & Fabaceae & Medicago sativa L. subsp. sativa & Karayonca & Kuru otlaklar & E1 & Bilinmiyor & SV 1693 \\
\hline 144 & Fabaceae & Melilotus indicus (L.) All. & Otuzlu yonca & Kuru otlaklar & E1 & Bilinmiyor & SV 1659 \\
\hline 145 & Fabaceae & Melilotus officinalis (L.) Desr. & Kokulu yonca & Kuru otlaklar & E1 & Bilinmiyor & SV 1832 \\
\hline 146 & Fabaceae & Ononis pubescens $\mathrm{L}$. & Havlı örsele & Kuru otlaklar & E1 & Akdeniz & SV 2449 \\
\hline 147 & Fabaceae & $\begin{array}{l}\text { Ononis spinosa L. subsp. leiosperma } \\
\text { (Boiss.) Sirj. }\end{array}$ & Demirdelen & Kuru otlaklar & E1 & Bilinmiyor & SV 1892 \\
\hline 148 & Fabaceae & $\begin{array}{l}\text { Ononis viscosa L.subsp. breviflora } \\
\text { (DC.) Nyman }\end{array}$ & Sidikli siyek & Kuru otlaklar & E1 & Akdeniz & SV 1627 \\
\hline 149 & Fabaceae & $\begin{array}{l}\text { Pisum sativum L. subsp. elatius var. } \\
\text { elatius Aschers. \& Graebn. }\end{array}$ & Boylu bezelye & Kuru otlaklar & E1 & Akdeniz & SV 1913 \\
\hline 150 & Fabaceae & Tetragonolobus purpureus Moench & $\mathrm{Al}$ canavardişi & Kuru otlaklar & E1 & Bilinmiyor & SV 2254 \\
\hline 151 & Fabaceae & Trifolium angustifolium $\mathrm{L}$. & Nefel & Kuru otlaklar & E1 & Bilinmiyor & SV 2187 \\
\hline 152 & Fabaceae & Trifolium arvense L.var. arvense & Tavşanayağı & Kuru otlaklar & E1 & Bilinmiyor & SV 2188 \\
\hline 153 & Fabaceae & $\begin{array}{l}\text { Trifolium campestre Schreb. subsp. } \\
\text { campestre }\end{array}$ & Üçgül & Kuru otlaklar & E1 & Bilinmiyor & SV 2190 \\
\hline 154 & Fabaceae & Trifolium dubium Sibth. & Tatlı yonca & Kuru otlaklar & E1 & Bilinmiyor & SV 2194 \\
\hline 155 & Fabaceae & $\begin{array}{l}\text { Trifolium fragiferum L.var. } \\
\text { fragiferum }\end{array}$ & Çilek üçgülü & Kuru otlaklar & $\mathrm{E} 1$ & Bilinmiyor & SV 2196 \\
\hline 156 & Fabaceae & Trifolium hirtum All. & Deli yonca & Kuru otlaklar & E1 & Akdeniz & SV 2200 \\
\hline 157 & Fabaceae & Trifolium repens L.var. repens & Ak üçgül & Kuru otlaklar & E1 & Bilinmiyor & SV 2209 \\
\hline
\end{tabular}




\begin{tabular}{|c|c|c|c|c|c|c|c|}
\hline 158 & Fabaceae & Trifolium scabrum L. & Hıyar dücük & Kuru otlaklar & E1 & Akdeniz & SV 2450 \\
\hline 159 & Fabaceae & $\begin{array}{l}\text { Trifolium resupinatum } \mathrm{L} \text {. var. } \\
\text { resupinatum }\end{array}$ & Anadoluüçgülü & Kuru otlaklar & E1 & Bilinmiyor & SV 2215 \\
\hline 160 & Fabaceae & Trifolium stellatum L. var. stellatum & Yildız yonca & Kuru otlaklar & E1 & Bilinmiyor & SV 2220 \\
\hline 161 & Fabaceae & Vicia cracca L. subsp. cracca & Kuş fiği & Sulanmayan karışı tarım alanları & $\mathrm{I} 2$ & Avrupa-Sibirya & SV 2225 \\
\hline 162 & Fabaceae & Vicia peregrina L. & Kavli & Kuru otlaklar & E1 & Bilinmiyor & SV 2228 \\
\hline 163 & Fabaceae & Vicia sativa L. subsp. sativa & Fiğ & Kuru otlaklar & E1 & Bilinmiyor & SV 2265 \\
\hline 164 & Fabaceae & $\begin{array}{l}\text { Vicia villosa Roth. subsp. } \\
\text { eriocarpa (Hausskn.) P.W.Ball. }\end{array}$ & Dağ efereği & Kuru otlaklar & E1 & Bilinmiyor & SV 2264 \\
\hline 165 & Gentianaceae & $\begin{array}{l}\text { Centaurium erythraea Rafn. } \\
\text { subsp. rhodense Melderis }\end{array}$ & Gelin düğmesi & Sulanmayan karışık tarım alanları & I2 & Akdeniz & SV 1885 \\
\hline 166 & Geraniaceae & $\begin{array}{c}\text { Erodium cicutarium } \text { (L.) L Hér. subsp. } \\
\text { cicutarium }\end{array}$ & İğnelik & $\begin{array}{c}\text { Büyük şehirlerin kenarında kalan } \\
\text { alanlar }\end{array}$ & J2 & Bilinmiyor & SV 1698 \\
\hline 167 & Geraniaceae & Geranium lucidum L. & Dakkaotu & Kuru otlaklar & E1 & Bilinmiyor & SV 1954 \\
\hline 168 & Geraniaceae & Geranium rotundifolium $\mathrm{L}$. & Helilok & Kuru otlaklar & E1 & Bilinmiyor & SV 2483 \\
\hline 169 & Hypericaceae & Hypericum triquetrifolium Turra & Pirpirotu & Kuru otlaklar & E1 & Bilinmiyor & SV 2473 \\
\hline 170 & Hypericaceae & $\begin{array}{l}\text { Hypericum perforatum subsp. } \\
\text { veronense (Schrank) H.Linb. }\end{array}$ & Sarıkantaron & Kuru otlaklar & E1 & Bilinmiyor & SV 1632 \\
\hline 171 & Juncaceae & Juncus acutus L. subsp. acutus & Kofa & $\begin{array}{c}\text { Yüzey suyu olmayan sazlıklar, kamış } \\
\text { yatakları }\end{array}$ & D5 & Bilinmiyor & SV 1691 \\
\hline 172 & Juncaceae & $\begin{array}{l}\text { Juncus articulatus L. subsp. } \\
\text { articulatus }\end{array}$ & Camışotu & $\begin{array}{c}\text { Yüzey suyu olmayan sazlıklar, kamış } \\
\text { yatakları }\end{array}$ & D5 & Avrupa-Sibirya & SV 2037 \\
\hline 173 & Juncaceae & Juncus effusus L. subsp. effusus & Haskofa & $\begin{array}{c}\text { Yüzey suyu olmayan sazlıklar, kamış } \\
\text { yatakları }\end{array}$ & D5 & Bilinmiyor & SV 1877 \\
\hline 174 & Juncaceae & Juncus gerardii Loisel. subsp. gerardii & Erkek kofa & $\begin{array}{c}\text { Yüzey suyu olmayan sazlıklar, kamış } \\
\text { yatakları }\end{array}$ & D5 & Bilinmiyor & SV 2487 \\
\hline 175 & Juncaceae & $\begin{array}{l}\text { Juncus heldreichianus T.Marsson ex } \\
\text { Parl. subsp. heldreichianus }\end{array}$ & Dombayotu & $\begin{array}{c}\text { Yüzey suyu olmayan sazlıklar, kamış } \\
\text { yatakları }\end{array}$ & D5 & Akdeniz & SV 1936 \\
\hline 176 & Juncaceae & Juncus inflexus L. subsp. inflexus & Sazak & $\begin{array}{c}\text { Yüzey suyu olmayan sazlıklar, kamış } \\
\text { yatakları }\end{array}$ & D5 & Bilinmiyor & SV 1630 \\
\hline 177 & Lamiaceae & $\begin{array}{l}\text { Ballota nigra L. subsp. } \\
\text { anatolica P.H.Davis }\end{array}$ & Giripotu & Kuru otlaklar & E1 & İran-Turan & SV 1882 \\
\hline 178 & Lamiaceae & $\begin{array}{l}\text { Lamium amplexicaule L.var. } \\
\text { amplexicaule }\end{array}$ & Baltutan & $\begin{array}{l}\text { Büyük şehirlerin kenarında kalan } \\
\text { alanlar }\end{array}$ & J2 & Bilinmiyor & SV 2430 \\
\hline 179 & Lamiaceae & $\begin{array}{l}\text { Lamium purpureum L var. } \\
\text { purpureum }\end{array}$ & Ballıbaba & Kuru otlaklar & E1 & Avrupa-Sibirya & SV 2429 \\
\hline 180 & Lamiaceae & $\begin{array}{l}\text { Mentha longifolia (L.) L. subsp. } \\
\text { typhoides (Briq.) Harley }\end{array}$ & Derenanesi & Kuru otlaklar & E1 & Bilinmiyor & SV 1891 \\
\hline 181 & Lamiaceae & Salvia verbenaca $\mathrm{L}$. & Elmakekiği & Kuru otlaklar & E1 & Akdeniz & SV 1850 \\
\hline 182 & Lamiaceae & Salvia virgata Jacq. & Fatmana otu & Kuru otlaklar & E1 & İran-Turan & SV 1951 \\
\hline 183 & Malvaceae & Althaea cannabina L. & Gülhannaz & Antropojenik bitki durumları & E5.1 & Bilinmiyor & SV 1880 \\
\hline 184 & Malvaceae & Malva neglecta Wallr. & Çobançöreği & Şehir merkezleri, sürekli bina yapıları & $\mathrm{J} 1$ & Bilinmiyor & SV 1903 \\
\hline 185 & Malvaceae & Malva sylvestris L. & Ebegümeci & Şehir merkezleri, sürekli bina yapıları & J1 & Bilinmiyor & SV 1953 \\
\hline 186 & Onagraceae & Epilobium hirsutum L. & Hasanhüseyin çiçeği & Antropojenik bitki durumları & E5.1 & Bilinmiyor & SV 1878 \\
\hline 187 & Orchidaceae & Serapias vomeracea (Burm.f.) Briq. & Sağırkulağı & Kuru otlaklar & E1 & Akdeniz & SV 1652 \\
\hline
\end{tabular}




\begin{tabular}{|c|c|c|c|c|c|c|c|}
\hline 188 & Orobanchaceae & Melampyrum arvense L.var. arvense & İnekbuğdayı & Kuru otlaklar & E1 & Avrupa-Sibirya & SV 1874 \\
\hline 189 & Orobanchaceae & $\begin{array}{l}\text { Orobanche alba Stephan ex Willd } \\
\text { subsp. alba }\end{array}$ & Boğasak & Kuru otlaklar & E1 & Bilinmiyor & SV 1918 \\
\hline 190 & Orobanchaceae & Orobanche nana Noë ex Reut. & Veremotu & Kuru otlaklar & E1 & Bilinmiyor & SV 2290 \\
\hline 191 & Orobanchaceae & $\begin{array}{l}\text { Parentucellia latifolia (L.) Caruel } \\
\text { subsp. Latifolia }\end{array}$ & Üçdilotu & Kuru otlaklar & E1 & Akdeniz & SV 2291 \\
\hline 192 & Papaveraceae & $\begin{array}{l}\text { Fumaria officinalis L. subsp. } \\
\text { officinalis }\end{array}$ & Şahtere & Kuru otlaklar & E1 & Bilinmiyor & SV 1623 \\
\hline 193 & Papaveraceae & $\begin{array}{l}\text { Hypecoum procumbens L. subsp. } \\
\text { atropunctatum A.E.Dahl. }\end{array}$ & Düğmecik & Kıyı kumulları ve kumlu kıyıları & B1 & Bilinmiyor & SV 2489 \\
\hline 194 & Papaveraceae & Papaver rhoeas L. & Gelincik & Kuru otlaklar & E1 & Bilinmiyor & SV 1884 \\
\hline 195 & Plantaginaceae & Plantago lanceolata $\mathrm{L}$. & Damarlica & Şehir merkezleri, sürekli bina yapıları & J1 & Bilinmiyor & SV 1932 \\
\hline 196 & Plantaginaceae & $\begin{array}{l}\text { Plantago coronopus L. subsp. } \\
\text { commutata Pilg. }\end{array}$ & Çı̆̆nak & Kıyı kumulları ve kumlu kıyıları & B1 & Akdeniz & SV 1906 \\
\hline 197 & Plantaginaceae & Plantago major L. subsp. major & Sinirotu & Şehir merkezleri, sürekli bina yapıları & J1 & Bilinmiyor & SV 2469 \\
\hline 198 & Plantaginaceae & $\begin{array}{l}\text { Plantago major L. subsp. } \\
\text { intermedia (Gilib.) Lange }\end{array}$ & Yedidamarotu & Şehir merkezleri, sürekli bina yapıları & J1 & Bilinmiyor & SV 2284 \\
\hline 199 & Plantaginaceae & Veronica arvensis L. & Ekinmavişi & Sulanmayan karışık tarım alanları & $\mathrm{I} 2$ & Avrupa-Sibirya & SV 1889 \\
\hline 200 & Plantaginaceae & Veronica biloba L. & Çifte maviş & Sulanmayan karışık tarım alanları & I2 & İran-Turan & SV 1904 \\
\hline 201 & Poaceae & Aegilops geniculata Roth. & Konbaş & Kuru otlaklar & E1 & Akdeniz & SV 1831 \\
\hline 202 & Poaceae & Agrostis stolonifera L. & Tavusotu & $\begin{array}{c}\text { Nadasa bırakılmış sulanmayan } \\
\text { alanlar }\end{array}$ & $\mathrm{I} 1.5$ & Avrupa-Sibirya & SV 2453 \\
\hline 203 & Poaceae & $\begin{array}{c}\text { Alopecurus myosuroides Huds. subsp. } \\
\text { myosuroides }\end{array}$ & Tarla tilkikuyruğu & $\begin{array}{c}\text { Nadasa bırakılmış sulanmayan } \\
\text { alanlar }\end{array}$ & $\mathrm{I} 1.5$ & Avrupa-Sibirya & SV 2467 \\
\hline 204 & Poaceae & Arundo donax L. & Karg1 & $\begin{array}{c}\text { Kalıcı oligotrofik göller, göletler ve } \\
\text { havuzlar }\end{array}$ & $\mathrm{C} 1.1$ & Bilinmiyor & SV 2479 \\
\hline 205 & Poaceae & $\begin{array}{c}\text { Avena barbata Pott ex Link subsp. } \\
\text { barbata }\end{array}$ & Narin yulaf & Kuru otlaklar & E1 & Akdeniz & SV 1672 \\
\hline 206 & Poaceae & Avena fatua L. var. glabrata Peterm. & Deli yulaf & $\begin{array}{l}\text { Bitki Örtüsünün Olmadığı ya da } \\
\text { Seyrek Bitki Örtülü Alanlar }\end{array}$ & C3.6 & Avrupa-Sibirya & SV 1895 \\
\hline 207 & Poaceae & Avena sterilis L. subsp. sterilis & Şifan & Kuru otlaklar & E1 & Bilinmiyor & SV 1621 \\
\hline 208 & Poaceae & Briza maxima L. & Kuşyüreği & Sulanmayan karışık tarım alanları & I2 & Bilinmiyor & SV 1803 \\
\hline 209 & Poaceae & Briza media L. & Zembilotu & Kuru otlaklar & E1 & Bilinmiyor & SV 2280 \\
\hline 210 & Poaceae & $\begin{array}{c}\text { Bromus hordeaceus L. subsp. } \\
\text { hordeaceus }\end{array}$ & Başakotu & Kuru otlaklar & E1 & Bilinmiyor & SV 2431 \\
\hline 211 & Poaceae & $\begin{array}{l}\text { Bromus japonicus Thunb. subsp. } \\
\text { japonicus }\end{array}$ & İyeotu & Kuru otlaklar & E1 & Bilinmiyor & SV 1846 \\
\hline 212 & Poaceae & Bromus riparius Rehm. & Meşe kılcanı & Kuru otlaklar & E1 & Bilinmiyor & SV 1677 \\
\hline 213 & Poaceae & Bromus scoparius L. & İbubuk ekini & Kuru otlaklar & E1 & Bilinmiyor & SV 1876 \\
\hline 214 & Poaceae & Bromus tectorum L. & Kır bromu & Kuru otlaklar & E1 & Bilinmiyor & SV 1809 \\
\hline 215 & Poaceae & $\begin{array}{c}\text { Chrysopogon gryllus (L.) Trin. subsp. } \\
\text { gryllus }\end{array}$ & Buzağıtu & Sulanmayan karışık tarım alanları & $\mathrm{I} 2$ & Bilinmiyor & SV 2034 \\
\hline 216 & Poaceae & $\begin{array}{c}\text { Cynodon dactylon (L.) Pers. var. } \\
\text { dactylon }\end{array}$ & Köpekdişi & Şehir merkezleri, sürekli bina yapıları & $\mathrm{J} 1$ & Bilinmiyor & SV 1830 \\
\hline
\end{tabular}




\begin{tabular}{|c|c|c|c|c|c|c|c|}
\hline 217 & Poaceae & Cynosurus echinatus $\mathrm{L}$. & Top tarakotu & Kuru otlaklar & E1 & Akdeniz & SV 2297 \\
\hline 218 & Poaceae & Echinochloa crus-galli (L.) P. Beauv. & Darıcan & $\begin{array}{c}\text { Nadasa bırakılmışs sulanmayan } \\
\text { alanlar }\end{array}$ & $\mathrm{I} 1.5$ & Bilinmiyor & SV 2496 \\
\hline 219 & Poaceae & $\begin{array}{l}\text { Elymus farctus (Viv.) Runemark ex } \\
\text { Melderis subsp. farctus }\end{array}$ & Cicora & Kuru otlaklar & $\mathrm{E} 1$ & Bilinmiyor & SV 2033 \\
\hline 220 & Poaceae & $\begin{array}{c}\text { Elymus flaccidifolius (Boiss. \& Heldr.) } \\
\text { Melderis }\end{array}$ & Bataklık cicorası & Kuru otlaklar & $\mathrm{E} 1$ & Bilinmiyor & SV 2432 \\
\hline 221 & Poaceae & $\begin{array}{c}\text { Festuca arundinacea Schreb. subsp. } \\
\text { arundinacea }\end{array}$ & Kamışyumağ & Kuru otlaklar & $\mathrm{E} 1$ & Bilinmiyor & SV 1839 \\
\hline 222 & Poaceae & $\begin{array}{c}\text { Festuca callieri (Hack.) Markgr. } \\
\text { subsp. callieri }\end{array}$ & Çarşak yumağı & Kuru otlaklar & $\mathrm{E} 1$ & Bilinmiyor & SV 2455 \\
\hline 223 & Poaceae & $\begin{array}{l}\text { Helictotrichon pubescens (Huds.) } \\
\text { Schult. \& Schult.f. }\end{array}$ & Kıllı yulaf & Kuru otlaklar & $\mathrm{E} 1$ & Avrupa-Sibirya & SV 1810 \\
\hline 224 & Poaceae & Hordeum bulbosum L. & Boncuk arpa & Şehir merkezleri, sürekli bina yapıları & J1 & Bilinmiyor & SV 1917 \\
\hline 225 & Poaceae & $\begin{array}{l}\text { Hordeum murinum L. subsp. } \\
\text { glaucum (Steud.) Tzvelev }\end{array}$ & Duvar arpası & $\begin{array}{c}\text { Büyük şehirlerin kenarında kalan } \\
\text { alanlar }\end{array}$ & $\mathrm{J} 2$ & Bilinmiyor & SV 1935 \\
\hline 226 & Poaceae & $\begin{array}{l}\text { Hordeum murinum L. subsp. } \\
\text { leporinum (Link) Arcang. }\end{array}$ & Kılçıkarpa & Şehir merkezleri, sürekli bina yapıları & J1 & İran-Turan & SV 1834 \\
\hline 227 & Poaceae & Lagurus ovatus L. & Tavşankuyruğu & Kuru otlaklar & E1 & Akdeniz & SV 2464 \\
\hline 228 & Poaceae & Lolium multiflorum Lam. & İtalyan çimi & Kuru otlaklar & E1 & Bilinmiyor & SV 2230 \\
\hline 229 & Poaceae & $\begin{array}{l}\text { Lolium temulentum } \mathrm{L} \text {. var. } \\
\text { temulentum }\end{array}$ & Delice çim & Kuru otlaklar & $\mathrm{E} 1$ & Bilinmiyor & SV 2236 \\
\hline 230 & Poaceae & Phalaris canariensis L. & Kuşyemi & $\begin{array}{c}\text { Kalıcı oligotrofik göller, göletler ve } \\
\text { havuzlar }\end{array}$ & $\mathrm{C} 1.1$ & Akdeniz & SV 1804 \\
\hline 231 & Poaceae & Phalaris paradoxa L. & Topuzlu kanyaş & $\begin{array}{c}\text { Kalıcı oligotrofik göller, göletler ve } \\
\text { havuzlar }\end{array}$ & $\mathrm{C} 1.1$ & Akdeniz & SV 2294 \\
\hline 232 & Poaceae & Phleum pratense $\mathrm{L}$. & Çayır itkuyruğu & $\begin{array}{c}\text { Kalıcı oligotrofik göller, göletler ve } \\
\text { havuzlar }\end{array}$ & $\mathrm{C} 1.1$ & Avrupa-Sibirya & SV 1961 \\
\hline 233 & Poaceae & Poa annua L. & Salkımotu & Kuru otlaklar & $\mathrm{E} 1$ & Bilinmiyor & SV 2471 \\
\hline 234 & Poaceae & Poa nemoralis $\mathrm{L}$. & Orman salkımı & Kuru otlaklar & E1 & Bilinmiyor & SV 1670 \\
\hline 235 & Poaceae & Poa pratensis $\mathrm{L}$. & Çayırsalkımotu & Kuru otlaklar & $\mathrm{E} 1$ & Bilinmiyor & SV 2457 \\
\hline 236 & Poaceae & Setaria viridis (L.) P.Beauv. & Yeşilsıçansaçı & Kuru otlaklar & E1 & Bilinmiyor & SV 2276 \\
\hline 237 & Poaceae & $\begin{array}{c}\text { Sorghum halepense (L.) Pers var. } \\
\text { halepense }\end{array}$ & Ekin süpürgesi & Kuru otlaklar & $\mathrm{E} 1$ & Bilinmiyor & SV 2273 \\
\hline 238 & Poaceae & Stipa bromoides (L.) Dörfll. & Kulaç & Kuru otlaklar & E1 & Akdeniz & SV 2272 \\
\hline 239 & Polygalaceae & Polygala monspeliaca L. & Mart sütotu & Kuru otlaklar & $\mathrm{E} 1$ & Akdeniz & SV 1678 \\
\hline 240 & Polygonaceae & Polygonum arenastrum Boreau & Bezmeceotu & Kuru otlaklar & E1 & Bilinmiyor & SV 1919 \\
\hline 241 & Polygonaceae & Polygonum lapathifolium L. & Tirşon & Kuru otlaklar & E1 & Bilinmiyor & SV 2463 \\
\hline 242 & Polygonaceae & Rumex acetosella L. & Kuzukulağı & Kuru otlaklar & $\mathrm{E} 1$ & Bilinmiyor & SV 1802 \\
\hline 243 & Polygonaceae & Rumex crispus L. & Labada & Kuru otlaklar & E1 & Bilinmiyor & SV 1679 \\
\hline 244 & Polygonaceae & Rumex patientia L. & Efelek & Kuru otlaklar & E1 & Bilinmiyor & SV 1952 \\
\hline 245 & Polygonaceae & Rumex pulcher L. subsp. pulcher & Ekşilik & $\begin{array}{c}\text { Nadasa bırakılmışs sulanmayan } \\
\text { alanlar }\end{array}$ & $\mathrm{I} 1.5$ & Bilinmiyor & SV 2488 \\
\hline 246 & Polygonaceae & $\begin{array}{l}\text { Rumex tuberosus L subsp. creticus } \\
\text { (Boiss.) Rech.f. }\end{array}$ & Humadotu & Kuru otlaklar & E1 & Akdeniz & SV 1841 \\
\hline
\end{tabular}




\begin{tabular}{|c|c|c|c|c|c|c|c|}
\hline 247 & Portulacaceae & Portulaca oleracea L. & Semizotu & Kuru otlaklar & E1 & Bilinmiyor & SV 1628 \\
\hline 248 & Primulaceae & Anagallis arvensis L. subsp. arvensis & Farekulağı & Antropojenik bitki durumları & E5.1 & Bilinmiyor & SV 1847 \\
\hline 249 & Ranunculaceae & Adonis flammea Jacq. & Cin lalesi & Antropojenik bitki durumları & E5.1 & Bilinmiyor & SV 2031 \\
\hline 250 & Ranunculaceae & Clematis vitalba L. & Akasma & Antropojenik bitki durumları & E5.1 & Bilinmiyor & SV 2249 \\
\hline 251 & Ranunculaceae & $\begin{array}{l}\text { Ranunculus ficaria L. subsp. } \\
\text { calthifolius (Rchb.) Arcang }\end{array}$ & Çöp salebi & Kuru otlaklar & E1 & Bilinmiyor & SV 2239 \\
\hline 252 & Ranunculaceae & Ranunculus repens L. & Tiktakdana & Kuru otlaklar & E1 & Bilinmiyor & SV 2240 \\
\hline 253 & Resedaceae & Reseda lutea L. var. lutea & Muhabbet çiçeği & Kuru otlaklar & E1 & Bilinmiyor & SV 2458 \\
\hline 254 & Rosaceae & Sarcopoterium spinosum (L.) Spach & Abdestbozan & Kuru otlaklar & E1 & Akdeniz & SV 2245 \\
\hline 255 & Rosaceae & Filipendula vulgaris Moench & Çayırmelikesi & Kuru otlaklar & E1 & Avrupa-Sibirya & SV 1907 \\
\hline 256 & Rosaceae & $\begin{array}{c}\text { Rubus canescens DC. subsp. } \\
\text { canescens }\end{array}$ & Çobankösteği & Kuru otlaklar & $\mathrm{E} 1$ & Avrupa-Sibirya & SV 2498 \\
\hline 257 & Rosaceae & Rubus sanctus Schreb. & Böğürtlen & Kuru otlaklar & E1 & Bilinmiyor & SV 1911 \\
\hline 258 & Rosaceae & $\begin{array}{l}\text { Sanguisorba minor Scop. subsp. } \\
\text { balearica Muñoz Garm. }\end{array}$ & Çayırdüğmesi & Kuru otlaklar & E1 & Bilinmiyor & SV 2241 \\
\hline 259 & Rubiaceae & Crucianella bithynica Boiss. & Çayır haçotu & Kuru otlaklar & E1 & Akdeniz & SV 1908 \\
\hline 260 & Rubiaceae & Galium aparine $\mathrm{L}$. & Çobansüzgeci & Kuru otlaklar & E1 & Bilinmiyor & SV 1902 \\
\hline 261 & Rubiaceae & Galium verum L.subsp. verum & Boyalık & Kuru otlaklar & E1 & Avrupa-Sibirya & SV 1915 \\
\hline 262 & Rubiaceae & Rubia peregrina $\mathrm{L}$. & Yabani kökboya & Kuru otlaklar & E1 & Akdeniz & SV 2289 \\
\hline 263 & Scrophulariaceae & Verbascum speciosum Schrad. & Zelve & Kuru otlaklar & E1 & Bilinmiyor & SV 2267 \\
\hline 264 & Scrophulariaceae & Verbascum blattaria L. & Tutansığırkuyruğu & Kuru otlaklar & E1 & Bilinmiyor & SV 2269 \\
\hline 265 & Solanaceae & Datura stramonium L. & Boruçiçeği & Şehir merkezleri, sürekli bina yapıları & $\mathrm{J} 1$ & Bilinmiyor & SV 2460 \\
\hline 266 & Typhaceae & Typha latifolia L. & Cil & $\begin{array}{c}\text { Kalıcı oligotrofik göller, göletler ve } \\
\text { havuzlar }\end{array}$ & $\mathrm{C} 1.1$ & Bilinmiyor & SV 2032 \\
\hline 267 & Urticaceae & Parietaria judaica L. & Duvarfesleğeni & Şehir merkezleri, sürekli bina yapıları & $\mathrm{J} 1$ & Bilinmiyor & SV 1933 \\
\hline 268 & Urticaceae & Urtica dioica L. subsp. dioica & Isırgan & Sulanmayan karışık tarım alanları & I2 & Avrupa-Sibirya & SV 2271 \\
\hline 269 & Xanthorrhoeaceae & Asphodeline lutea (L.) Rchb. & Sarı çiriş & Kuru otlaklar & E1 & Akdeniz & SV 2461 \\
\hline 270 & Xanthorrhoeaceae & Asphodelus aestivus Brot. & Kirgiçkökü & Kuru otlaklar & E1 & Bilinmiyor & SV 2462 \\
\hline 271 & Zygophyllaceae & Tribulus terrestris $\mathrm{L}$. & Çobançökerten & Şehir merkezleri, sürekli bina yapıları & J1 & Bilinmiyor & SV 2459 \\
\hline
\end{tabular}




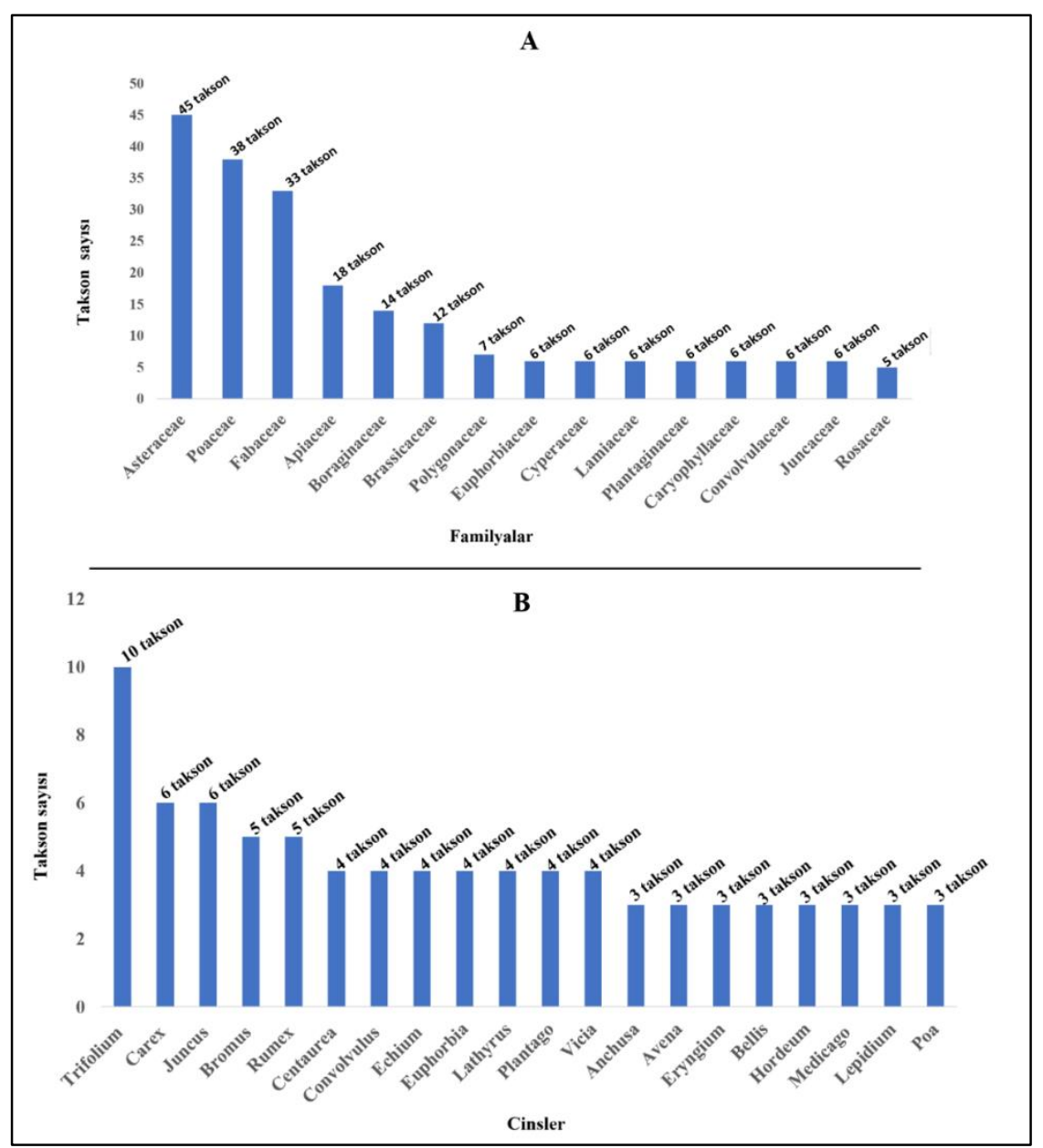

Şekil 2. En fazla taksona sahip olan familyalar (A) ve cinsler (B)

Figure 2. Families (A) and genera (B) with the most number of taxa

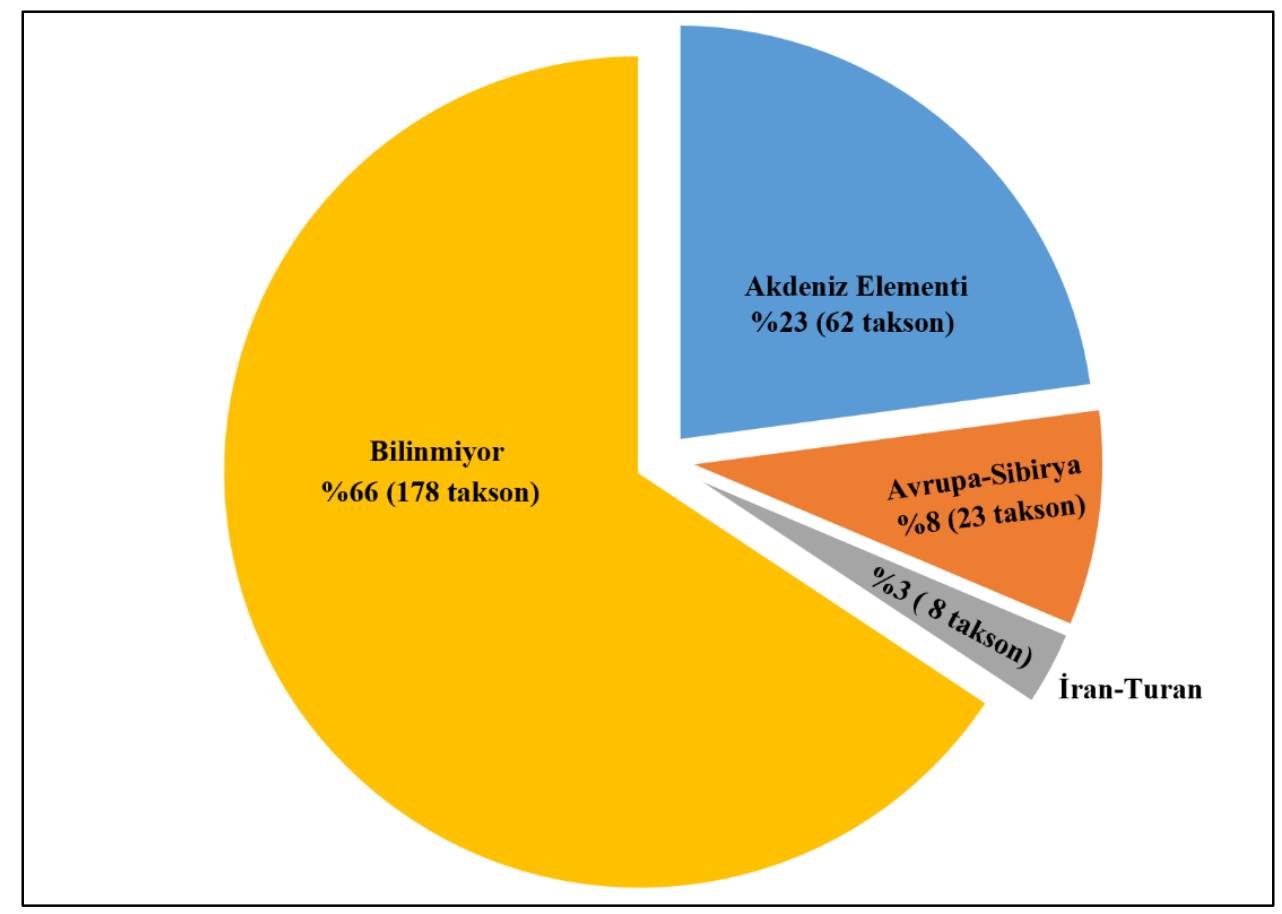

Şekil 3. İstilacı karaktere sahip yerli taksonların fitocoğrafik elementlere göre dağılımı Figure 3. Distribution of native plant taxa with invasive character according to phytogeographic elements 


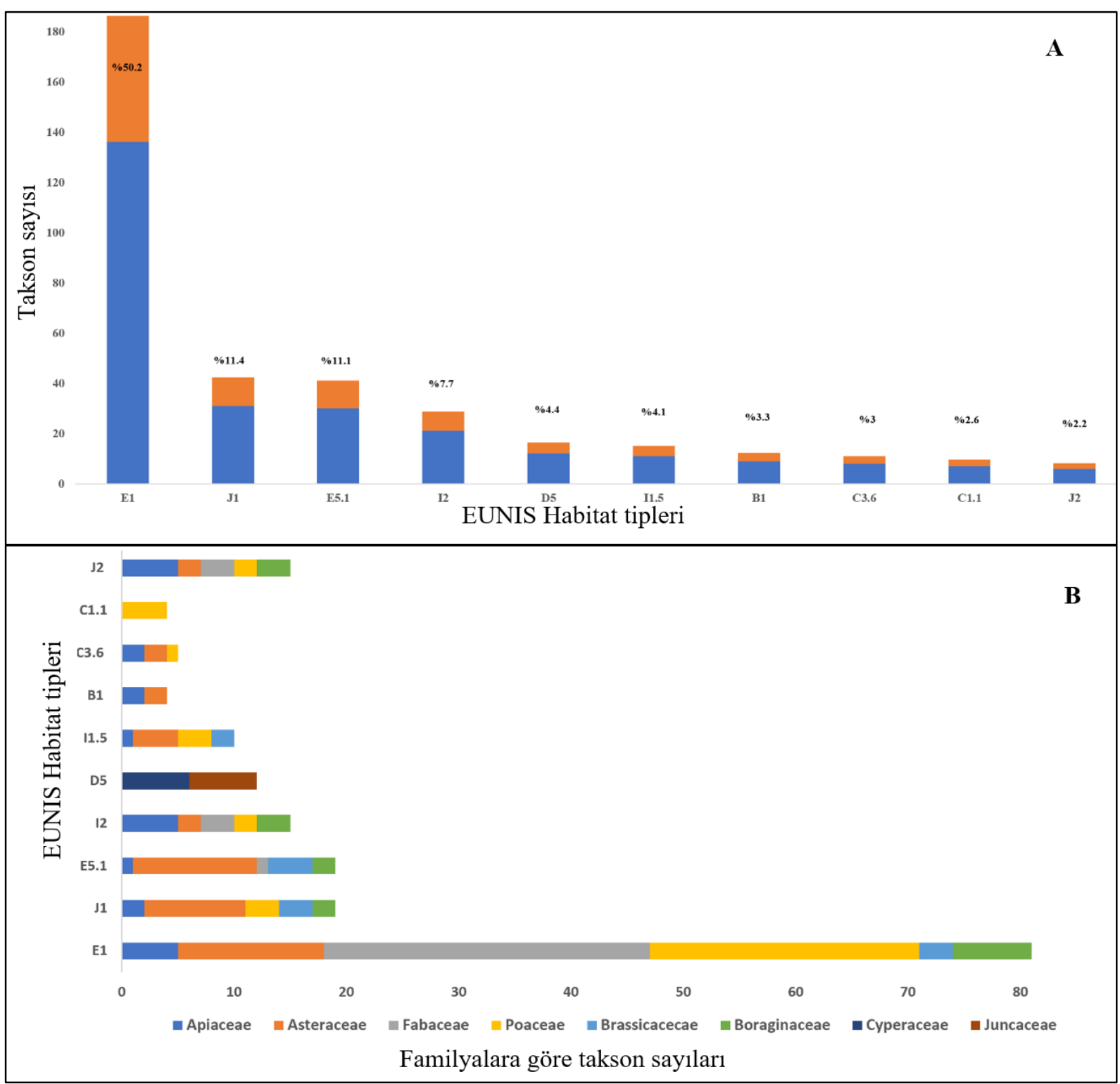

Şekil 4. Taksonların habitat tiplerine göre dağılım grafiği (A) ve habitat tiplerine göre en fazla taksona sahip familyalar (B) Figure 4. Graph of distribution of taxa according to habitat types and the familia with the most number of taxa according to habitat type

yaygın olduğu görülmüştür. Aynı şekilde, Centaurea solstitialis üzerinde yapılan başka bir araştırmada ise farkl müdahalelerin $C$. solstitialis populasyon büyüklüğünü ve verimliliğini arttırdığı tespit edilmiştir (Hierro ve ark., 2006). C. solstitialis Balıkesir ve çevresindeki boş alanlarda oldukça yoğun bir yayılışa sahiptir. İstilacı türler, ülkemizde de bulundukları bölgenin ekolojik dengesini bozarak çevreye kalıcı zararlar vermektedirler. İstilacı türler, habitatların tahrip edilmesi ve küresel iklim değişikliğiyle birlikte biyolojik çeşitlilik zarar veren en önemli tehditlerden biri olarak kabul edilmektedir (Charudattan, 2001). Davis ve ark. (2000)'nin geliştirdiği 'Müdahale Hipotezi, tahribatın komünitede doğal yayılış gösteren bitkilerin kapladığı alanı azalttığını ya da yerli bitki topluluklarında doğrudan ölüme neden olduğunu savunmaktadır. Çalışmamızda da bu hipoteze göre müdahale edilmiş boş alanlarda istilacı karaktere sahip yerli türlerin yoğun yayılış gösterdiği gözlenmiştir. $C$. solstitialis üzerinde gerçekleştirilmiş olan deneysel bir çalışmada müdahale sonrası $C$. solstitialis in bulunuşunun, popülasyon büyüklüğünün ve verimliliğinin türün anavatanı dışında anavatanına oranla daha fazla arttırdığ 1 gösterilmiştir (Hierro ve ark., 2006).

Familyaların EUNIS habitat tiplerine göre dağılımında tür kompozisyonunun en büyük kısmını, kuru otlaklarda (E1) Fabaceae (29 takson) ve Poaceae (24 takson), Şehir merkezleri, sürekli bina yapıları (J1)'nda Asteraceae (9 takson) ve Brassicaceae (3 takson), Antropojenik bitki ortamlarında (E5.1) Asteraceae (9 takson) ve Brassicaceae (3 takson), 
Sulanmayan karışık tarım alanları'nda (I2) Apiaceae (5 takson) ve Boraginaceae (3 takson); Yüzey suyu olmayan sazlıklar, kamış yatakları (D5)' nda Cyperaceae ve Juncaceae (6' sar takson); Nadasa bırakılmış sulanmayan alanlarda (I1.5) Asteraceae (4 takson) ve Poaceae (3 takson); Kıyı kumulları ve kumlu kıyıları (B1)' nda Apiaceae, Asteraceae ve Apocynaceae (2'şer takson); Bitki örtüsünün olmadığg ya da Seyrek bitki örtülü alanlarda (C3.6) Apiaceae ve Asteraceae (2'şer takson); Kalıcı oligotrofik göller, göletler ve havuzlar (C1.1)' da Poaceae (4 takson) ve Equisetaceae (3 takson); Büyük şehirlerin kenarında kalan alanlar (J2)' da ise Asteraceae (2 takson) familyası üyeleri oluşturmaktadır (Çizelge 2; Şekil 4, $5)$.

Cizelge 3. Balıkesir ilinde tespit edilen EUNIS Habitat tipleri ve baskın cinsler

Table 3. EUNIS Habitat types and dominant genera detected in Ballkesir province

\begin{tabular}{|c|c|c|c|}
\hline $\begin{array}{l}\text { EUNIS Habitat Tipi } \\
\text { (EUNIS Habitat type) }\end{array}$ & $\begin{array}{l}\text { EUNIS Kodu } \\
\text { (EUNIS Code) }\end{array}$ & $\begin{array}{l}\text { Toplam takson sayisı } \\
\text { (Total taxon number) }\end{array}$ & $\begin{array}{l}\text { Habitat tipinde baskin cins } \\
\text { (Dominant genus in habitat } \\
\text { type) }\end{array}$ \\
\hline Kuru otlaklar & E1 & 136 & Trifolium (10 takson) \\
\hline Şehir merkezleri, sürekli bina yapıları & J1 & 31 & Plantago (3 takson) \\
\hline Antropojenik bitki durumları & E5.1 & 30 & $\begin{array}{l}\text { Anchusa, } \begin{array}{c}\text { Centaurea, } \\
\text { Convolvulus, Conyza (2 takson) }\end{array}\end{array}$ \\
\hline Sulanmayan karışık tarım alanları & $\mathrm{I} 2$ & 21 & Eryngium (3 takson) \\
\hline Yüzey suyu olmayan sazlıklar, kamış yatakları & D5 & 12 & Carex, Juncus (6 takson) \\
\hline Nadasa bırakılmış sulanmayan alanlar & $\mathrm{I} 1.5$ & 11 & Cichorium (1 takson) \\
\hline Kıyı kumulları ve kumlu kıyıları & B1 & 9 & Centaurea (1 takson) \\
\hline $\begin{array}{l}\text { Bitki Örtüsünün Olmadığı ya da Seyrek Bitki } \\
\text { Örtülü Alanlar }\end{array}$ & C3.6 & 8 & Avena (1 takson) \\
\hline Kalıcı oligotrofik göller, göletler ve havuzlar & C1.1 & 7 & Phalaris, Equisetum (2 takson) \\
\hline Büyük şehirlerin kenarında kalan alanlar & J2 & 6 & Cirsium, Lamium (1 takson) \\
\hline
\end{tabular}

Cinslerin habitat tiplerine göre dağılımında alanda en fazla yayılış gösteren cinsler ve takson sayıları Çizelge 3 ' te verilmiştir. Çizelge incelendiğinde en fazla taksona sahip habitat tipinin E1. Kuru otlaklar olduğu ve en baskın cinsinde 10 takson ile Trifolium olduğu görülmektedir.

Çalışma alanında tespit edilen istilacı karaktere sahip yerli türlerin botanik ve ekolojik özelliklerine bakıldığında; hızlı büyüme gösterdiği, yaşam döngülerinin kısa sürdüğü, derin kök sistemlerine sahip oldukları ve çok sayıda tohum ürettikleri görülmüştür. "Niş boşluğu hipotezi"”ne göre de $C$. solstitialisin sahip olduğu yaygın ve derin kök sistemi bitkiye, diğer bazı bitkilerin sığ kök sistemleri tarafindan 'kullanılamayan su kaynaklarından faydalanma potansiyeli sağlamaktadır. Bu durum $C$. solstitialisin istilacı başarısını destekleyen etmenlerden biri olarak görülmektedir (Borman ve ark., 1992; Holmes ve Rice, 1996; Dyer ve Rice, 1999).

Bunların yanı sıra, literatürlerde de belirtildiği gibi istilac1 türlerin; birçok ekolojik faktör için toleranslarının yüksek olması, vejetatif üreme stratejilerini kullanmaları, sahip oldukları sekonder metabolitler ile rekabet üstünlükleri ve herbivorlara karşı dirençli olmaları vb. özellikleri de yeni ortamlara uyum kabiliyetlerini artırmışlardır. Benzer durum, Valéry ve ark. (2008)'a göre, aynı temel rekabet mekanizmalarına sahip olmaları nedeniyle yerli istilacı türler için de geçerlidir. Örneğin Sürmen ve ark. (2015)'ın Samsun ilinde 106 çayır ve merada yaptığ istilacı türünün önemli populasyon yoğunluğuna sahip olduğu bulunmuştur. Benzer şekilde Balıkesir ve çevresindeki boş alanlarda ve çayır/mera alanlarında $X$ spinosum oldukça yoğun populasyonlar oluşturmaktadır. $\mathrm{Bu}$ çalışmada bölgedeki istilacı karaktere sahip yerli türlerin oluşturdukları ekonomik hasarlar tam olarak belirlenemese de genel olarak ağır ekonomik hasarlara sebep olacağı tahmin edilmektedir. $\mathrm{Bu}$ konuda yapılan çalışmalar sonucunda; Amerika'da istilacı bitkilerden kaynaklanan kayıpların yıllı 26 milyar \$, Avustralya'da 3.6-4.5 milyar AUS\$, Yeni Zelanda da ise 200 milyon NZ\$ olduğu tahmin edilmektedir. Mevut durum için hesaplanan bu maliyetler eğer istilacı bitkilerin potansiyel yayılma sinırlarına ulaşmaları halinde daha da yukarılara çıkabileceği belirtilmektedir (Önen, 2015). Sonuç olarak; istilacı türlerin bu derece yaygın bir sorun haline gelmesi; iklim değişikliğinin ortaya çıkardığı uygun koşullar, arazi kullanımındaki dönüşümler gibi büyük oranda insan etkileri sonucunda ortaya çıkan yeni koşulların bir sonucudur. Balıkesir florasındaki istilacı karaktere sahip yerli türler de bölgenin konumu, jeolojik, iklimsel ve biyolojik çeşitlilik yapısı gereği ve istilacı bitki türlerine yönelik mücadelelerin yetersiz oluşu ve yoğun inşaat faaliyetleri neticesinde oluşan uygun ortam vb. nedenlerle büyük bir risk/tehdit faktörü olmaya devam etmektedir. Biyolojik çeşitliliği tehdit 
eden ve ciddi ekonomik kayıplara yol açan istilacı tür istilası acil çözüm bekleyen en önemli sorunlarından birisidir. Bölgede bilinçsiz ve aşırı otlatma, çayır ve meralarda otlatmaya karşı dirençli olan yerli ve yabancı istilacı türlerin yerleşmesine firsat sağlamıştır. Bu durum alanın floristik yapısının değişmesi sonucunda çayır ve mera kalitesinin düşmesi ve tür zenginliğinin azalmasina sebep olmaktadır. -

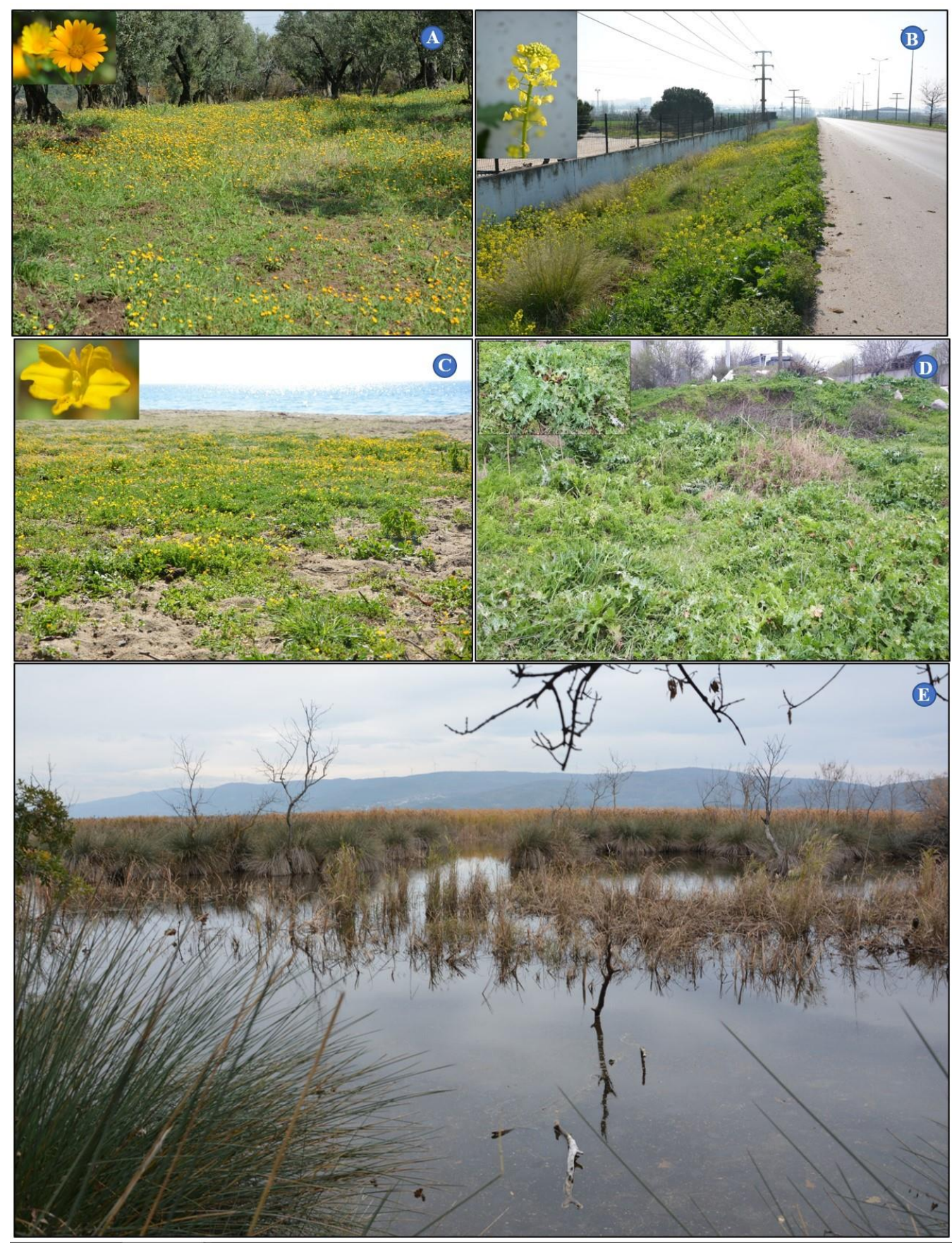

Şekil 5. Balıkesir'de istilacı karaktere sahip yerli taksonların yayılış gösterdiği habitat tipleri. A) E1. Çayırlık ortamlar (Calendula arvensis topluluğu) B) J1. Yol kenarları (Sinapis alba subsp. alba topluluğu). C) D1. Kumul ortamlar (Hypecoum procumbens subsp. atropunctatum topluluğu), D) J1. Şehir içi harabe ortamlar (Silybum marianum subsp. marianum topluluğu), E) D5. Sulak alanlar (Carex ve Juncus toplulukları)

Figure 5. Habitat types where native plant taxa with invasive character in Balıkesir. A) E1. Meadow environments (Calendula arvensis community) B) J1. Roadsides (Sinapis alba subsp. alba community). C) D1. Dune environments (Hypecoum procumbens subsp. atropunctatum community), D) J1. Urban ruin environments (Silybum marianum subsp. marianum community), E) D5. Wetlands (Carex and Juncus communities) 
$\mathrm{Bu}$ nedenle bu türlerin yayılış alanları belirli periyotlarla gözlemlenmeli ve gerekli önlemler alınmalıdır. Yerli ve yabancı istilacı türlerin yayılımını önlemek amaciyla, türler teşhis edildikten sonra, bu konuda yetkili olan paydaşlara (bakanlıklar, üniversiteler, STK'lar vb. kurum veya kuruluşların ilgili birimleri), durumun bildirilmesi gerekir. Bununla birlikte önemli görülen türler için acil müdahale çerçevesinde; yayılmanın önlenmesi amacıyla Gider (2013)'in de belirttiği gibi aşağıdaki uygun yöntemler kullanılabilir;

1. Alandaki istilacı bitkinin ve her türlü çoğalma aracinın (tohum, vejetatif organ vb.) tamamen yok edilebilir (Eradikasyon),

2. İstilacı bitkiler kök sisteminden kazılmak suretiyle yok edilebilir,

3. İstilacı bitkilerin bastırılması ve yayılmasını engellenmek amacıyla hızlı çimlenen, çabuk gelişen, geniş habitüslü ve toprağı hızlıca örten bitkiler kullanılabilir,

4. İstilacı türleri yakılabilir,

5. Biyolojik mücadele olarak böcekler kullanılabilir,

6. Herbisit uygulaması yapılabilir,

Yüksek iş gücü gerektirmemesi ve kolay uygulanması ayrıca diğer önlemlere oranla daha etkili ve ekonomik olması nedeniyle herbisit kullanımı istilacı bitkilerin mücadelesinde başvurulan en yaygin önlemlerdendir.

\section{Çıkar Çatışması Beyanı}

Makale yazarları aralarında herhangi bir çıkar çatışması olmadığını beyan ederler.

\section{Araştırmacıların Katkı Oranı Beyan Özeti}

Yazarlar makaleye eşit oranda katkı sağlamış olduklarını beyan ederler.

\section{KAYNAKLAR}

Açar M, Satıl F 2014. Flora of Akdağ (Balıkesir, Dursunbey/Turkey). BioDiCon 7(2): 38-56.

Altman S, Whitlatch RB 2007. Space invaders: the effect of small-scale disturbance on invasion success in marine communities. J Exp Mar Biol Ecol 342: 15-29.

Anonim 2008. Türkiye'nin Çayır ve Mera Bitkileri. T.C. Tarım ve Köy İşleri Bakanlığı, Tarımsal Üretim ve Geliştirme Genel Müdürlüğü. Çayır, Mera, Yem Bitkileri ve Havza Geliştirme Daire Başkanlığı. $468 \mathrm{~s}$

Anonim 2017. Balıkesir İli'nin karasal ve iç su ekosistemleri biyolojik çeşitlilik envanter ve izleme projesi. Ulusal Biyolojik Çeşitlilik Envanter ve İzleme Projesi (UBENIS). T.C. Tarım ve Orman Bakanlığı, Doğa Koruma ve Milli Parklar Genel Müdürlüğü, Ankara.
Anonim 2019. EUNIS habitat type hierarchical view. https://eunis.eea.europa.eu/habitats-code-browser. jsp?expand=\#level_G

Anonim 2020a. Global Invasive Species Database. Downloaded from http://www.iucngisd.org/ gisd/ search.php on 24-05-2020.

Anonim 2020b. Terrestrial Plants. http://www. invasivespeciesinfo.gov/ plants/

Borman MM, Johnson DE, Krueger WC 1992. Soil moisture extraction by vegetation in a mediterranean/maritime climate regime. Agron J 84: 897-904

Boz Ö 2000. Aydın İli pamuk ekim alanlarındaki yabancı otların yaygınlık ve yoğunluklarının saptanması. Turk J Weed Sci 3(1): 10-16.

Callaway RM, Aschehoug ET 2000. Invasive plants versus their new and old neighbors: a mechanism for exotic invasion. Science 290: 521-523.

Catford JA, Daehler CC, Murphy HT, Sheppard AW, Hardesty BD, Westcott DA, Rejmánek M, Bellingham PJ, Pergl J, Horvitz CC, Hulme PE 2012. The intermediate disturbance hypothesis and plant invasions: implications for species richness and management. Perspectives in Plant Ecology. Annu Rew Ecol Evol Syst 14: 231-241.

Charudattan R 2001. Biological control of weeds by means of plant pathgens: Significance for integrated weed management in modern agroecology. BioControl 49: 229-260.

Çoruh I, Zengin H 2009. Erzurum yöresinde yonca ekim alanlarinda bulunan yabancı otlar, yoğunlukları ve rastlama sıklıkları. Atatürk Üniv Ziraat Fak Derg 40(1): 49-53.

Davis MA, Grime JP, Thompson K 2000. Fluctuating resources in plant communities: a general theory of invasibility. J Ecol 88: 528-534.

Dirmenci T (2006). Gölcük (Dursunbey-Balıkesir) florası üzerine bir çalışma, Ot Sist Bot Dergisi 13 (1): 97-124.

Doğan S, Özen F 1999. Değirmenboğazı (Balıkesir) ve Çevresinin Florası, Ot Sist Bot Dergisi, 6(1): 17-38.

Dyer AR, Rice KJ 1999. Effect of competition on resource availability and growth of a California bunchgrass. Ecology 80: 2697-2710.

Eren, Ö. 2010. Centaurea solstitialis L. (Çakır Dikeni, Asteraceae) Türünün İstilacı Özelliğini Tetikleyen Etkenlerin Araştırılması, TÜBİTAK TBAG, Proje No: 106T507.

Eriksen RL, Hierro JL, Eren Ö, Andonian K, Török K ve ark. 2014. Dispersal Pathways and Genetic Differentiation among Worldwide Populations of the Invasive Weed Centaurea solstitialis L. (Asteraceae). PLoS ONE 9(12): e114786. doi:10.1371/journal.pone.0114786.

Gider P 2013. İstilacı bitki türlerinin ve istila yeteneklerinin tek ylllk otlaklarda ve yol kenarlarında (Aydın, Denizli, Muğla, İzmir) 
belirlenmesi. Adnan Menderes Üniversitesi Fen Bilimleri Enstitüsü Biyoloji Anabilim Dalı, Yüksek Lisans Tezi, 81 sy.

Güner A, Aslan S, Ekim T, Vural M, Babaç, MT (edlr.) 2012. Türkiye Bitkileri Listesi (Damarlı Bitkiler). Nezahat Gökyiğit Botanik Bahçesi ve Flora Araştırmaları Derneği Yayınları, İstanbul.

Güner Ö, Akçiçek E 2013. Flora of Ulus Mountain (Balıkesir/Turkey), BioDiCon 6(1): 101-113.

Hierro JL, Villareal D, Eren O, Graham JM, Callaway RM 2006. Disturbance facilitates invasion: the effects are stronger abroad than at home. Am Nat, 168:144-156.

Holmes TH, Rice KJ 1996. Patterns of growth and soilwater utilization in some exotic annuals and native perennial bunchgrasses of California. Ann Bot 78: 233-243

Karaer F, Kutbay HG, Terzioğlu, S 2015. Türkiye'nin İstilacı Yabancı Bitki Biyoçeşitliliği, Tehdit Faktörleri ve Alınması Gerekli Tedbirler. Turk J Weed Sci 18(1-2): 24-32.

Kayaçetin, F 2020. Botanical characteristics, potential uses, and cultivation possibilities of mustards in Turkey: a review. Turk J Bot 44(2): 101-127.

Lake JC, Leishman MR 2004. Invasion success of exotic plants in natural ecosystems: the role of disturbance, plant attributes and freedom from herbivores. Biol Conserv 117: 215-226.

MacDougall AS, Turkington R 2005. Are exotic species the drivers or passengers of ecological change in highly disturbed plant communities? Ecology 86: $42-55$.

Önen H 2015. Türkiye İstilacı Bitkiler Kataloğu. T.C. Gıda, Tarım ve Hayvancılık Bakanlığı Tarımsal Araştırmalar ve Politikalar Genel Müdürlüğü Bitki Sağlığı Araştırmaları Daire Başkanlığı, Ankara, 533 sy.

Özkil M, Üremiş İ 2019. Tarla sarmaşı̆̆ (Convolvulus arvensis L.) ve pembe çiçekli akşamsefası (Ipomoea triloba L.)'nın çimlenme biyolojisi üzerinde araştırmalar. Bitki Kor Bülteni 59(4): 3-10.

Richardson DM, Pyšek P, Rejmánek M, Barbour MG, Panetta FD, West CJ 2000. Naturalization and invasion of alien plants: concepts and definitions. Diversity Distrib 6: 93-107.

Satıl F, Tümen G, Selvi S 2019a. Ayvalık (Balıkesir/Turkey) Dune Plant Diversity, Threatening Factors and Solution Proposals. J Inst Sci and Tech 9(3): 1289-1298.
Satıl F, Tümen G, Selvi S 2019b. Gönen deltası kumul bitki çeşitliliği, tehdit faktörleri ve çözüm önerileri. AÇÜ Orman Fak Derg 20(2): 208-217.

Strid A, Tan K 1986. Mountain of Greece, Vol. 1-2, Edinburg.

Sürmen M, Yavuz T, Sürmen B, Kutbay H 2015. Samsun İli Çayır ve Mera Alanlarında İstilacı Türlerin Tespiti ve Yoğunluklarının Belirlenmesi. Turk J Weed Sci 18(1): 1-5.

Terzioğlu S, Coşkunçelebi K, Başkent EZ 2014. İtdolanbacı (Sicyos angulatus L.) Tür Mücadele Eylem Planı (20152017), T.C. Orman ve Su İşleri Bakanlığı DKMP Genel Müdürlüğü, Ankara, 25 sy.

Tutin GT, Heywood VH 1964-1981. Flora of Europae, Cambridge University Press, Vol. 1-4.

Tümen G, Satıl F, Selvi S 2018. Manyas (BandırmaBalıkesir) Kuş Cenneti ve Çevresinin Florası Üzerine Araştırmalar. International Symposium of Bandirma and Its Surroundings-UBS'18. pp. 397415, September 17-19, 2018/BandirmaBalıkesir/TURKEY.

Türe C, Köse YB 2000. Eskişehir ve çevresindeki bazı tarım alanlarında yayılış gösteren yabancı ot florası üzerinde bir araştırma. Turk J Agr For 24: 327-331.

Özer Z, Önen H, Tursun N, Uygur FN 1999. Türkiye’nin Bazı Önemli Yabancı Otları (Tanımları ve Kimyasal Savaşımları), Gaziosmanpaşa Üniversitesi Ziraat Fakültesi Yayınları No: 38, Kitaplar Serisi No: 16, Tokat.

Uygur FN, Koch W, Walter H 1984. Yabanc1 Ot Bilimine Giriş. PLITS, 2(1), Verlog J. Margraf, Stuttgart, Germany, 114 sy.

Uygur S, Smith L, Uygur N, Cristofaro M 2004. Population densities of yellow starthistle (Centaurea solstitialis) in Turkey. Weed Science 52:746-753.

Valéry L, Fritz H, Lefeuvre J, Simberloff D 2008. In search of a real definition of the biological invasion phenomenon itself. Biol Invasions 10: 1345-1351.

Valéry L, Fritz H, Lefeuvre JC, Simberloff D 2009a. Invasive species can also be native. Trends in Ecology and Evolution Vol.24(11): 585.

Valéry L, Fritz H, Lefeuvre JC, Simberloff D 2009b. Ecosystem-level consequences of invasions by native species as a way to investigate relationships between evenness and ecosystem function. Biol Invasions 11: 609-617.

Yıldırım A, Ekim T 2003. Orta Anadolu Bölgesi yabancı ot florası. Bitki Kor Bülteni 43(1-4): 1-98. 